\section{Check for updates}

Cite this: Dalton Trans., 2021, 50 660

\title{
Electronic and geometric structure effects on one- electron oxidation of first-row transition metals in the same ligand framework $\dagger$
}

\author{
Manuel Boniolo, (D) a Petko Chernev, (D) a Mun Hon Cheah, (D) a Philipp A. Heizmann, ${ }^{b}$ \\ Ping Huang, (D) a Sergii I. Shylin, (DD ${ }^{a}$ Nessima Salhi, ${ }^{a, c}$ Md Kamal Hossain, (D) ${ }^{b}$ \\ Arvind K. Gupta, ${ }^{\mathrm{b}}$ Johannes Messinger, (D) *a,d Anders Thapper (D) ${ }^{* b}$ and \\ Marcus Lundberg (D) *a,c
}

\begin{abstract}
Developing new transition metal catalysts requires understanding of how both metal and ligand properties determine reactivity. Since metal complexes bearing ligands of the Py5 family (2,6-bis-[(2-pyridyl)methyl] pyridine) have been employed in many fields in the past 20 years, we set out here to understand their redox properties by studying a series of base metal ions $(\mathrm{M}=\mathrm{Mn}, \mathrm{Fe}, \mathrm{Co}$, and $\mathrm{Ni}$ ) within the $\mathrm{Py} 5 \mathrm{OH}$ (pyridine-2,6-diylbis[di-(pyridin-2-yl)methanol]) variant. Both reduced $\left(M^{\prime \prime}\right)$ and the one-electron oxidized $\left(\mathrm{M}^{\mathrm{II}}\right)$ species were carefully characterized using a combination of X-ray crystallography, X-ray absorption spectroscopy, cyclic voltammetry, and density-functional theory calculations. The observed metal-ligand interactions and electrochemical properties do not always follow consistent trends along the periodic table. We demonstrate that this observation cannot be explained by only considering orbital and geometric relaxation, and that spin multiplicity changes needed to be included into the DFT calculations to reproduce and understand these trends. In addition, exchange reactions of the sixth ligand coordinated to the metal, were analysed. Finally, by including published data of the extensively characterised Py5OMe (pyridine-2,6-diylbis[di-(pyridin-2-yl)methoxymethane])complexes, the special characteristics of the less common Py5OH ligand were extracted. This comparison highlights the non-innocent effect of the distal $\mathrm{OH}$ functionalization on the geometry, and consequently on the electronic structure of the metal complexes. Together, this gives a complete analysis of metal and ligand degrees of freedom for these base metal complexes, while also providing general insights into how to control electrochemical processes of

transition metal complexes.
\end{abstract}

Received 26th October 2020 Accepted 1st December 2020 DOI: $10.1039 / \mathrm{d} 0 \mathrm{dt} 03695 \mathrm{a}$ rsc.li/dalton

\section{Introduction}

The optimization of multi-step redox catalysis performed by molecular complexes requires a fundamental understanding of the factors that determine performance. Redox potentials of individual one-electron processes, the coupling of electron and

\footnotetext{
${ }^{a}$ Molecular Biomimetics, Department of Chemistry - Ångström Laboratory, Uppsala University, 75120 Uppsala, Sweden.

E-mail: johannes.messinger@kemi.uu.se, marcus.lundberg@kemi.uu.se ${ }^{b}$ Synthetic Molecular Chemistry, Department of Chemistry - Ångström Laboratory, Uppsala University, 75120 Uppsala, Sweden. E-mail: anders.thapper@kemi.uu.se ${ }^{c}$ Theoretical Chemistry, Department of Chemistry - Ångström Laboratory, Uppsala University, 75120 Uppsala, Sweden

${ }^{d}$ Department of Chemistry, Chemical Biological Centre, Umeå University, 90187 Umeå, Sweden

$\dagger$ Electronic supplementary information (ESI) available. CCDC 2013481-2013483. For ESI and crystallographic data in CIF or other electronic format see DOI: 10.1039/d0dt03695a
}

proton transfer and the binding affinities of reactants and products are often intertwined properties that only a systematic experimental and theoretical study can disentangle. ${ }^{1}$ As the properties of coordination complexes are determined by the metalligand interactions, such analysis should describe their influence in a systematic manner. ${ }^{2}$ Presently available studies where the metal site is varied within the same coordination sphere mainly focus on a phenomenological description without developing deep insight into the reasons for different reactivities. ${ }^{3,4}$ Here we begin to fill this gap by a detailed study of one-electron redox reactions in a series of first-row transition metal complexes with the same pentapyridyl ligand framework (Fig. 1). This fundamental approach makes it possible to focus initially on the role of the metal in a well-defined reaction step, followed by a separate analysis of the ligand dimension.

The family of pentapyridyl ligands stemming from Py5, (2,6-bis-[(2-pyridyl)methyl]pyridine) has been extensively adopted in the past two decades to complex different first-row 


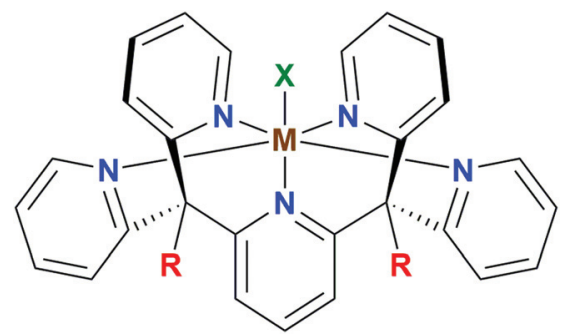

Fig. 1 General structure of the pentapyridyl family of metal complexes ( $M=$ metal centre, $R=$ ligand substituent, $X=$ apical ligand).

transition metals. ${ }^{5}$ Feringa et al. reported the first example of $\mathrm{Fe}^{\mathrm{II}}$ and $\mathrm{Mn}^{\mathrm{II}}$ complexes with the methoxy-substituted ligand (Py5OMe), highlighting how the apical coordination site is particularly prone to ligand substitution and therefore can reversibly bind possible substrate candidates for catalytic reactions. ${ }^{6}$ Simultaneously, Stack et al. studied catalytic applications of the same complexes for the oxidation of organic substrates as they mimic the cofactor of lipoxygenases. ${ }^{7-9}$ This team also reported structural parameters, magnetic susceptibility, electrochemical behaviour, and optical properties of the series of $[\mathrm{M}(\mathrm{Py} 5 \mathrm{OMe}) \mathrm{Cl}]^{+}(\mathrm{M}=\mathrm{Mn}, \mathrm{Fe}, \mathrm{Co}, \mathrm{Ni}, \mathrm{Cu}$ and $\mathrm{Zn})$ complexes, but only in their reduced $\mathrm{M}^{\mathrm{II}}$ oxidation state. ${ }^{4}$ During the following two decades, Py5 complexes have also been applied as anti-tumour agents, ${ }^{10,11}$ redox mediators for dye-sensitized solar cells, ${ }^{12,13}$ and materials with tunable magnetic properties. ${ }^{14-16}$ In the field of the artificial photosynthesis, Py5-type ligands have been reported to be a suitable scaffold for synthesizing both proton reduction ${ }^{17-20}$ and water oxidation catalysts. ${ }^{21-24}$

With the idea of creating a starting point for further functionalization, our group introduced the $\mathrm{Py} 5 \mathrm{OH}$ ligand and employed it in homogeneous water oxidation catalysis using either $\mathrm{Co}^{\mathrm{II}}$ or $\mathrm{Fe}^{\mathrm{II}}$ as the metal centre. ${ }^{25,26}$ Our recent study on the $\left[\mathrm{Fe}^{\mathrm{II}}(\mathrm{Py} 5 \mathrm{OH}) \mathrm{Cl}\right]^{+}$complex showed that, unlike $\left[\mathrm{Fe}^{\mathrm{II}}(\mathrm{Py} 5 \mathrm{OMe}) \mathrm{Cl}\right]^{+}$, it undergoes a spin-crossover from a high spin (HS) to low spin (LS) configuration, even in the presence of a weak-field ligand like $\mathrm{Cl}^{15}$ This infers that the peripheral R-groups of the ligand can affect the electronic structure of the metal centre.

Using the Py5OH ligand framework (Fig. 1; R = OH) we synthesized here a series of metal complexes with the general formula $\left[\mathrm{M}^{\mathrm{II}}(\mathrm{Py} 5 \mathrm{OH}) \mathrm{Cl}\right]\left(\mathrm{PF}_{6}\right)$ (abbreviated as $\left.\left[\mathbf{M}^{\mathrm{II}}-\mathbf{C l}\right]\right)$, where $\mathrm{M}=\mathrm{Mn}, \mathrm{Fe}$, Co and Ni. Their one-electron redox potentials were then determined by cyclic voltammetry, and the geometric and electronic structures of both the reduced $\left[\mathbf{M}^{\mathrm{II}}-\mathbf{C l}\right]$ and oxidized $\left[\mathbf{M}^{\mathrm{III}}-\mathbf{C l}\right]$ species were investigated in powder and/or dissolved form by employing a combination of singlecrystal X-ray diffraction (XRD), synchrotron X-ray absorption spectroscopy (XAS) and density-functional theory (DFT) calculations.

The effect of the ligand sphere on the redox potential was then studied by exchange of the apical chloride ligand. This is especially interesting with regard to catalytic reactions as its exchangeability is likely important for substrate activation. To facilitate this, we also prepared the Cl-free $\left[\mathrm{Fe}^{\mathrm{II}}(\mathrm{Py} 5 \mathrm{OH}) \mathrm{MeOH}\right]$ $\left(\mathrm{ClO}_{4}\right)_{2}$ complex, which upon dissolving in dimethylformamide or acetonitrile resulted in two additional set of complexes: [Fe $\left.{ }^{\mathrm{II}}-\mathbf{D M F}\right]$ and $\left[\mathbf{F e}^{\mathrm{II}}-\mathbf{M e C N}\right]$. Finally, the electrochemical properties of the $\left[\mathbf{M}^{\mathbf{I I}}-\mathbf{C l}\right]$ complexes were compared to those reported previously for $\left[\mathrm{M}^{\mathrm{II}}(\mathrm{Py} 5 \mathrm{OMe}) \mathrm{Cl}\right]^{+}$, abbreviated $\left[\mathbf{M}^{\mathbf{I I}}-\mathbf{C l}\right]^{\mathbf{O M e}}$. Together, this work represents a consistent set of modifications for the pentapyridyl complexes in Fig. 1, varying metal (M), apical ligand (X) and pentapyridyl substituent (R). Combined with the careful experimental and theoretical analysis of a well-defined one-electron redox event, this provides fundamental insight into the electrochemical processes of transition metal complexes.

\section{Results and discussion}

\subsection{Structures of divalent metal complexes}

Single-crystal XRD structures were obtained for all four [ $\mathbf{M}^{\mathrm{II}}-$ Cl] complexes, out of which the $\left[\mathbf{M n}^{\mathrm{II}}-\mathbf{C l}\right]$ (Fig. S1 $\dagger$ ) and $\left[\mathbf{N i}^{\mathbf{I I}_{-}}\right.$ Cl] (Fig. 2) structures are reported for the first time. The structures for $\left[\mathbf{F e}^{\text {II }}-\mathbf{C l}\right]$ and $\left[\mathbf{C o}^{\text {II }}-\mathbf{C l}\right]$ from the present study showed good agreement with those published previously. ${ }^{25,26}$ In all the complexes, the transition metal was embedded in a pocket composed of the five pyridines with a sixth-axial chloride ligand. The metal environment had approximate local $C_{4 \mathrm{v}}$ symmetry with the $\mathrm{Fe}-\mathrm{Cl}$ vector along the $C_{4}$-proper axis.

Fig. 3 shows that all the metal-nitrogen bond distances (average of the equatorial $\mathrm{M}-\mathrm{N}_{\text {eq. }}$, blue; axial $\mathrm{M}-\mathrm{N}_{\text {axial }}$, red) decreased following the order of the periodic table, for $\mathrm{M}$ $\mathrm{N}_{\text {axial }}$ from $2.249 \AA$ in $\left[\mathbf{M n}^{\mathrm{II}}-\mathbf{C l}\right]$ to $2.065 \AA$ in $\left[\mathrm{Ni}^{\mathrm{II}}-\mathbf{C l}\right]$. This was not the case for the metal-chlorine bond distance: although the $\mathrm{Mn}-\mathrm{Cl}$ bond $(2.458 \AA$ ) was longer than the $\mathrm{Fe}-\mathrm{Cl}$ bond $(2.419 \AA)$, it increased again for the subsequent Co
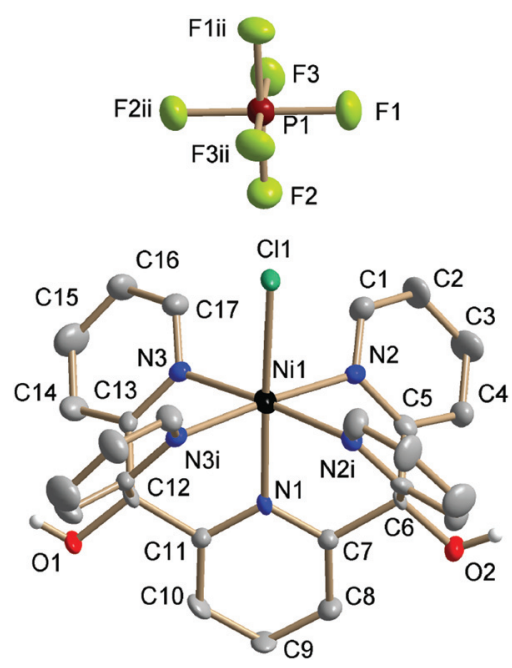

Fig. 2 Crystal structure of [ $\left.\mathrm{Ni}^{\prime \prime}-\mathrm{Cl}\right]$ collected at $150 \mathrm{~K}$. Thermal ellipsoids are drawn at the $50 \%$ probability level. Non-hydroxyl $\mathrm{H}$ atoms are omitted for clarity. Symmetry codes: (i) $x,-1.5-y, z$; (ii) $-x,-1-y, z$. 


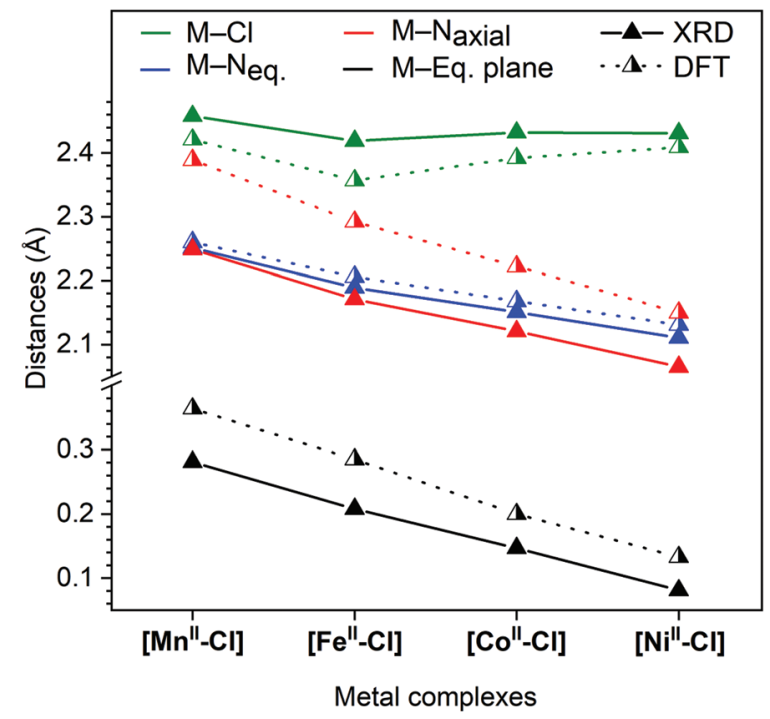

Fig. 3 Comparison of distances from single-crystal X-ray diffraction collected at $150 \mathrm{~K}$ (full triangle, solid line) and calculated distances using DFT; (half-filled triangle, dotted line). M-Eq. plane, metal displacement from the equatorial plane, which is defined by the four nitrogen atoms: N2, N2i, N3 and N3i (see Fig. 2).

(2.432 ̊) and Ni (2.431 ̊̊) complexes, see Fig. 3 (green). These comparatively long metal-ligand distances are consistent with a high-spin (HS) configuration for all four $\left[\mathbf{M}^{\mathrm{II}}-\mathbf{C l}\right]$ complexes.

Finally, the metal displacement from the equatorial plane followed a linear trend from $0.281 \AA$ to $0.081 \AA$ in the order $\mathrm{Mn}>\mathrm{Fe}>\mathrm{Co}>\mathrm{Ni}$ (Fig. 3, black).

The solid $\left[\mathbf{M}^{\mathrm{II}}-\mathbf{C l}\right]$ complexes were further characterized in powder form (see Experimental section for elemental analyses) by X-ray absorption spectroscopy (XAS) at $20 \mathrm{~K}$. All the complexes exhibited K-edge XANES energy positions that matched the values of divalent reference metal complexes, see Fig. S3S6. $\dagger$ The simulated distances, obtained from the EXAFS measurements at $20 \mathrm{~K}$ of the solid $\left[\mathbf{M n}{ }^{\mathrm{II}}-\mathbf{C l}\right],\left[\mathbf{C o}^{\mathrm{II}}-\mathbf{C l}\right]$ and $\left[\mathrm{Ni}^{\mathrm{II}}-\mathrm{Cl}\right]$ samples, did not deviate significantly from those determined by XRD at $150 \mathrm{~K}$. However, the EXAFS spectrum of $\left[\mathrm{Fe}^{\mathrm{II}}-\mathrm{Cl}\right]$ indicated a significantly shorter $\mathrm{Fe}-\mathrm{N}_{\text {eq. }}$ distances, by approximately $0.2 \AA$. As we reported recently, this is due to a spin-state change (spin-crossover, $\mathrm{SCO}$ ) from quintet ${ }^{5}\left[\mathrm{Fe}^{\mathrm{II}}-\mathrm{Cl}\right]$ to singlet ${ }^{1}\left[\mathrm{Fe}^{\mathrm{II}}-\mathrm{Cl}\right]$ that occurs at a temperature below $80 \mathrm{~K}$ in the microcrystalline powder sample. ${ }^{15}$

To get closer to the conditions of the CV experiments, the XAS parameters were also obtained after dissolving the four samples in acetonitrile with electrolyte. The XAS spectra of the $\left[\mathbf{M n}^{\mathrm{II}}-\mathbf{C l}\right], \quad\left[\mathbf{C o}^{\mathrm{II}}-\mathbf{C l}\right]$ and $\left[\mathbf{N i}^{\mathrm{II}}-\mathbf{C l}\right]$ complexes remained unchanged as compared to the spectra recorded for the powder samples (see Fig. S3-S6†). By contrast, large differences in the XAS spectra were observed for $\left[\mathrm{Fe}^{\mathrm{II}}-\mathrm{Cl}\right]$ under the two conditions. A reasonable XAS fit of the dissolved Fe-complex at $20 \mathrm{~K}$ could be obtained with three components: (i) $40 \%$ of the chloride-bound LS form that was also observed for the powder, (ii) $40 \%$ of a HS form with long metal-ligand bonds, and (iii) $20 \%$ of a LS structure where the chloride ligand had exchanged with a solvent molecule. This was supported by a good EXAFS fit at $150 \mathrm{~K}$ where only two components, $80 \%$ of (ii) and $20 \%$ (iii), were necessary (see Fig. S8 and S9†). Dissolving the sample in an electrolyte solution thus led to partial ligand exchange and incomplete SCO down to $20 \mathrm{~K}$.

The electronic and geometric structures of the $\left[\mathrm{M}^{\mathrm{II}}-\mathbf{C l}\right]$ complexes were calculated for all spin multiplicities consistent with $3 \mathrm{~d}^{n}$ configurations $(n=5-8)$. Correct spin-state energetics are in general challenging to calculate with DFT due to strong functional dependence. $^{27-30}$ The results are especially sensitive to the amount of HF exchange, but as the functional dependence varies with the type of bonding it is difficult to get accurate results for a wide range of complexes. ${ }^{29}$ To address this challenge, we used the $\mathrm{SCO}$ in $\left[\mathrm{Fe}^{\mathrm{II}}-\mathrm{Cl}\right]$ as a reference point for selecting the functional. ${ }^{15}$

For $\left[\mathrm{Fe}^{\mathrm{II}}-\mathrm{Cl}\right]$ the B3LYP* functional (15\% HF exchange) gave good results. It favoured the quintet over the singlet by $5.3 \mathrm{kcal}$ $\mathrm{mol}^{-1}$ at room temperature, see Fig. 4 . This value was $2.2 \mathrm{kcal}$ $\mathrm{mol}^{-1}$ higher than what can be expected from the determined spin-transition temperature of the powder sample at $80 \mathrm{~K} .{ }^{15}$ As the solvated chloride-coordinated sample had remaining HS species down to $20 \mathrm{~K}$, the B3LYP* calculations with $15 \% \mathrm{HF}$ exchange should thus represent the complex in solution with relatively high accuracy. Calculations of the other complexes showed that they all favour high-spin states, even more so than iron, see Fig. 4 (blue bars) and Table S2. $\dagger$ At RT, the spin-state energetics for $\left[\mathbf{C o}^{\mathrm{II}}-\mathbf{C l}\right]$ was very close to that of $\left[\mathrm{Fe}^{\mathrm{II}}-\mathbf{C l}\right]$, but compared to $\left[\mathrm{Fe}^{\mathrm{II}}-\mathrm{Cl}\right]$ the LS form of the Co-complex was less well-stabilized at low temperatures, so that the calculations did not predict this to be a spin-crossover complex, see Table S5. $\dagger$

The corresponding DFT geometric structures were, in general, in good agreement with XRD data, see Fig. 3 and Table 1. The Fe- $\mathrm{N}_{\text {eq. }}$ distances had absolute deviations of less than $0.02 \AA$, which meant that trends in bond distances were

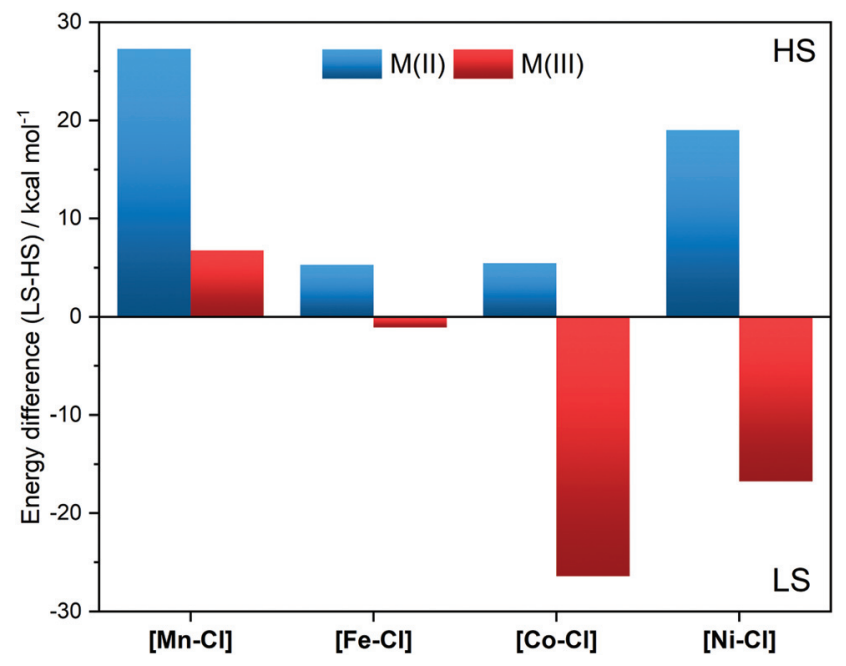

Fig. 4 Relative free energies at $298 \mathrm{~K}$ of the high-spin states compared to the low-spin states for $\left[\mathrm{M}^{\prime \prime}-\mathrm{Cl}\right]$ and $\left[\mathrm{M}^{\prime \prime \prime}-\mathrm{Cl}\right]$ complexes calculated using the B3LYP* functional and the SMD solvation model for acetonitrile. Note that the species used as the LS form of the $d^{8}\left[\mathrm{Ni}^{\prime \prime}-\mathrm{Cl}\right]$ requires pairing of electrons in one of the two upper $\mathrm{d}$ orbitals. 
Table 1 Metal-ligand distances (Å) derived from single-crystal X-ray diffraction (XRD), synchrotron X-ray absorption (EXAFS), and DFT calculations. EXAFS data were obtained at $20 \mathrm{~K}$ from complexes dissolved in acetonitrile with electrolyte, while XRD data were collected at $150 \mathrm{~K}$. Fit errors for EXAFS distances were $\sim 0.01 \AA$

\begin{tabular}{|c|c|c|c|c|c|c|c|c|c|c|}
\hline Complex & Ox. state & \multicolumn{3}{|c|}{$\mathrm{M}-\mathrm{N}_{\mathrm{eq}}$} & \multicolumn{3}{|c|}{$\mathrm{M}-\mathrm{N}_{\text {axial }}$} & \multicolumn{3}{|l|}{$\mathbf{M}-\mathrm{X}^{a}$} \\
\hline & III & - & $2.14^{c}$ & $2.158^{d}$ & - & $2.14^{c}$ & $2.116^{d}$ & - & $2.22^{c}$ & $2.264^{d}$ \\
\hline \multirow[t]{2}{*}[\mathrm{Fe}-\mathrm{Cl}]{} & II & 2.189 & $1.99^{e}$ & 2.206 & 2.171 & $1.99^{e}$ & 2.292 & 2.419 & $2.38^{e}$ & 2.357 \\
\hline & III & - & 1.99 & 2.034 & - & 1.99 & 2.049 & - & 2.22 & 2.249 \\
\hline [Co-Cl] & II & 2.151 & 2.14 & 2.168 & 2.121 & 2.14 & 2.222 & 2.432 & 2.40 & 2.392 \\
\hline & III & - & - & 1.993 & - & - & 2.193 & - & - & 2.420 \\
\hline & II & 2.017 & 1.98 & 2.040 & 1.952 & 1.98 & 2.032 & 1.989 & 1.98 & 1.933 \\
\hline & III & - & 1.97 & 2.015 & - & 1.97 & 2.026 & - & 1.97 & 1.945 \\
\hline
\end{tabular}

${ }^{a}$ For XRD, the apical ligand $\mathrm{X}$ is chloride for all $\left[\mathbf{M}^{\mathrm{II}}-\mathbf{C l}\right]$ complexes and the oxygen of DMF for the [Fe $\left.{ }^{\mathrm{II}}-\mathbf{S o l v}\right]$ complex. For EXAFS and DFT of $\left[\mathrm{Fe}^{\mathrm{II}}-\mathrm{Solv}\right]$ the apical ligand is the nitrogen of an acetonitrile molecule. ${ }^{b}$ Average of all $\mathrm{M}-\mathrm{N}$ distances modelled as one shell. ${ }^{c}$ Distorted ${ }^{5}\left[\mathrm{Mn}^{\mathrm{III}}-\right.$ Cl] after a least-squares EXAFS fit that allows for the distances to the three closest $\mathrm{N}$ atoms and the $\mathrm{Cl}^{-}$to be optimized $\left({ }^{5}\left[\mathbf{M n}^{\mathrm{II}}-\mathrm{Cl}^{\prime}\right]^{\prime}\right.$. ${ }^{d}$ Calculated distances for ${ }^{5}\left[\mathbf{M n}^{\mathrm{III}}-\mathbf{C l}\right]^{\prime}$ structure. ${ }^{e} \mathrm{Fe}-\mathrm{N}$ distance: single shell $\mathrm{Fe}-\mathrm{N}$ distance obtained in the best EXAFS fits employing a sample composition of $40 \% \mathrm{HS}, 40 \% \mathrm{LS}$, and $20 \%$ chloride substituted LS complex; Fe-Cl distance: average of $50 \% \mathrm{HS}$ and $50 \%$ LS complexes.

also well reproduced. The agreement is poorer for the axial bonds, with too short $\mathrm{M}-\mathrm{Cl}$ bonds $(-0.1 \AA$ on average) and much too long for $\mathrm{M}-\mathrm{N}_{\text {axial }}$ bonds ( $+0.2 \AA$ on average). This led to calculated metal centre positions that were further displaced from the equatorial plane than measured by XRD (by $0.1 \AA$ ). However, the structural trends were still very well reproduced, with all $\mathrm{M}-\mathrm{N}$ distances ( $\mathrm{M}-\mathrm{N}_{\text {eq. }}$ and $\mathrm{M}-\mathrm{N}_{\text {axial }}$ ) decreasing following the order in the periodic table, while the $\mathrm{M}-\mathrm{Cl}$ distances showed the above-described deviation for Co and Ni.

The choice of functional and basis set size did not affect the calculated distances by more than $0.02 \AA$, see Table S3, $\dagger$ and the very long $\mathrm{Fe}-\mathrm{N}_{\text {axial }}$ bond is present also with the local BP86 functional. Despite the deviations of the axial bond distances, the HS structures still give the best agreement with experiment. Structures with lower spin multiplicities all have significantly shorter $\mathrm{Fe}-\mathrm{N}_{\text {eq. }}$. bonds, which led to an underestimation by $0.2 \AA$, with no significant improvement in the Fe- $\mathrm{N}_{\text {axial }}$ distance, see Table $\mathrm{S} 2 . \dagger$

\subsection{Electrochemistry}

In cyclic voltammetry (CV) experiments, sweeping from the equilibrium potential towards the positive direction, reversible oxidation processes were observed for all $\left[\mathrm{M}^{\mathrm{II}}-\mathbf{C l}\right]$ complexes (Fig. 5). This was tentatively assigned to a metal-centred oneelectron oxidation from $\left[\mathbf{M}^{\mathrm{II}}-\mathbf{C l}\right] \rightarrow\left[\mathbf{M}^{\mathrm{III}}-\mathbf{C l}\right]$. The experimentally determined order of the reduction potentials of the redox couple $\left[\mathbf{M}^{\mathrm{III}}-\mathbf{C l}\right] /\left[\mathbf{M}^{\mathrm{II}}-\mathbf{C l}\right]$ was: Co $(0.08 \mathrm{~V})<\mathrm{Fe}(0.33 \mathrm{~V})<\mathrm{Mn}$ $(0.58 \mathrm{~V})<\mathrm{Ni}(1.17 \mathrm{~V})$, which deviates from the trend of increasing potentials along the periodic table that may be expected on the basis of increasing nuclear charge density. The vertical lines in Fig. 5 indicate the calculated redox potentials, which will be discussed in detail after describing the characterization of the oxidized complexes. In the case of [ $\left.\mathrm{Fe}^{\mathrm{II}}-\mathbf{C l}\right]$, a second reversible redox wave at $E_{1 / 2}=0.83 \mathrm{~V}$ was observed, which had an overlapping shoulder feature at $E_{\mathrm{p}}=0.72 \mathrm{~V}$ in the oxidative scan (marked with ${ }^{*}$ in Fig. 5). This shoulder feature was assigned to

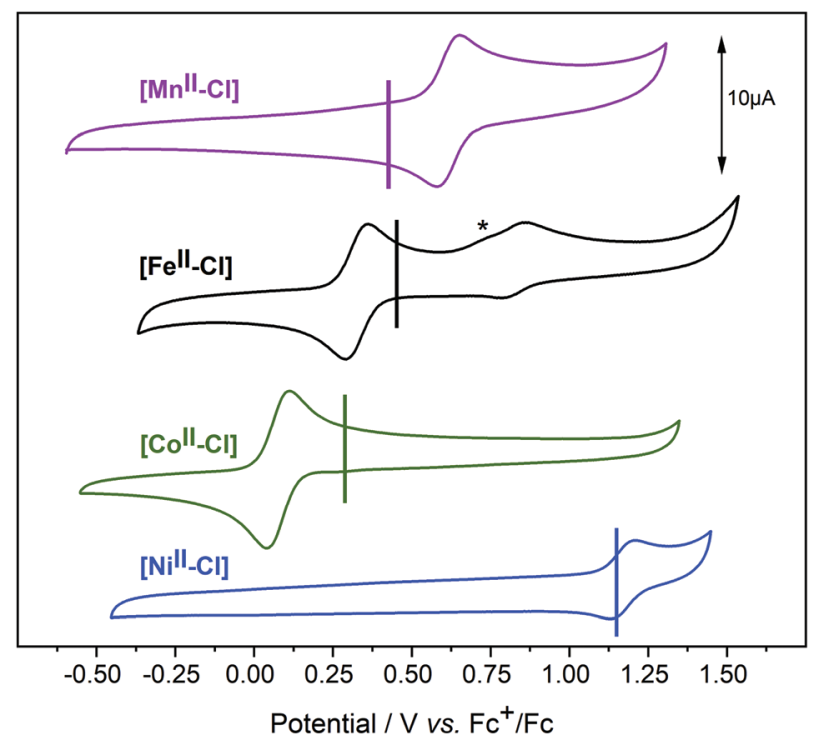

Fig. 5 Cyclic voltammograms of the $\left[\mathrm{M}^{\prime \prime}-\mathrm{Cl}\right]$ complexes in acetonitrile. The CVs were recorded under argon with a sample concentration of $0.5 \mathrm{mM}$ and $0.1 \mathrm{M}$ of TBAPF 6 as supporting electrolyte. Scan rate $100 \mathrm{mV}$ $\mathrm{s}^{-1}$. Vertical lines indicate the calculated redox potentials for the III/II oxidation, using the B3LYP* functional and the SMD solvation model for acetonitrile. The anodic current marked as * is assigned to the $\mathrm{Cl}^{-}$oxidation.

the quasi-reversible response of the redox-active couple $\mathrm{Cl}_{2} / \mathrm{Cl}^{-}$ by the observed increase of this feature after addition of tetrabutylammonium chloride (TBACl) to [ $\left.\mathrm{Fe}^{\mathrm{II}}-\mathrm{Cl}\right]$ (Fig. $\left.\mathrm{S} 10^{\dagger}\right)$ and by a separate voltammogram of TBACl (Fig. S11†). The second reversible redox wave was likely not an additional one-electron oxidation of $\mathrm{Fe}^{\mathrm{III}}$ to $\mathrm{Fe}^{\mathrm{IV}}$, since there was a significant difference in current intensity between the two waves. Instead, the higher redox potential feature likely arose from a secondary species that, based on the cathodic peak analysis, made up about $25 \%$ of the total compound. 
Given the observation of the irreversible $\mathrm{Cl}_{2} / \mathrm{Cl}^{-}$redox wave, the most likely candidate was the complex where the $\mathrm{Cl}^{-}$ ligand was replaced by a solvent molecule, which was also observed in the EXAFS data. This possibility will be analysed in detail in a later section.

We note that due to the difference in temperature between the experiments, the $\mathrm{LS}^{\mathbf{1}}\left[\mathbf{F e}^{\mathbf{I I}}-\mathbf{C l}\right]$ species observed with EXAFS at $20 \mathrm{~K}$ was not present in the room temperature $\mathrm{CV}$ experiment. Thus, we estimate that the room temperature composition was $75 \%$ HS ${ }^{5}\left[\mathrm{Fe}^{\mathrm{II}}-\mathbf{C l}\right]$ and $25 \%{ }^{1}\left[\mathrm{Fe}^{\mathrm{II}}-\mathbf{M e C N}\right]$, in good agreement with the CV peak analysis.

\subsection{Structures of oxidized complexes}

To understand the redox potentials, also the products of the one-electron oxidation need to be analysed. Thus, the metal complexes were electrochemically oxidized in acetonitrile and analysed with XAS. The K-edge positions of the oxidized materials displayed a shift to higher energy compatible with a complete one-electron metal oxidation, see Fig. S3-6.† The only exception was the $\left[\mathbf{N i}^{\mathbf{I I}}-\mathbf{C l}\right]$ complex, for which its high redox potential did not allow us to yield a significant amount of the oxidized form with our continuous flow electrosynthesis cell. Oxidation of the three remaining $\left[\mathbf{M n}^{\text {II }}-\mathbf{C l}\right],\left[\mathrm{Fe}^{\text {II }}-\mathbf{C l}\right]$ and $\left[\mathbf{C o}^{\text {II }}\right.$ Cl] complexes resulted for $\left[\mathbf{M n}^{\mathbf{I I}}-\mathbf{C l}\right]$ and $\left[\mathbf{C o}^{\mathbf{I I}}-\mathbf{C l}\right]$ in the expected shortening of the metal-ligand bonds as visible by significant changes in the $k$-space data, as well as by the shift of the first peak in the Fourier transform (Fig. 7a and b; Table 1). These structural changes observed by EXAFS spectroscopy are compared below with distances obtained by DFT calculations.

Oxidation of the $\left[\mathbf{M n}^{\mathrm{II}}-\mathbf{C l}\right]$ complex shortened the average $\mathrm{Mn}-\mathrm{N}$ distance by about $0.11 \AA$ and the $\mathrm{Mn}-\mathrm{Cl}$ distance by $0.21 \AA$ (Table 1). A direct EXAFS fit of the oxidized form requires a large Debye-Waller factor when a single $\mathrm{Mn}-\mathrm{N}$ shell is used (0.085 $\AA$, compared to around $0.065 \AA$ for the other complexes, see Table $\mathrm{S} 4 \dagger$ ), indicating a large Jahn-Teller distortion. DFT calculations of the oxidized Mn complex give the lowest energy for a quintet ${ }^{5}\left[\mathbf{M n}^{\mathrm{III}}-\mathbf{C l}\right]$ structure (Fig. 4 ), with the triplet ${ }^{3}\left[\mathbf{M n}^{\mathrm{III}}-\mathbf{C l}\right]$ $6.7 \mathrm{kcal} \mathrm{mol}^{-1}$ higher in energy (Table S2 $\dagger$ ). Compared to the reduced complex, the calculations on the ${ }^{5}\left[\mathbf{M n}^{\text {III-}}-\mathbf{C l}\right]$ reproduced qualitatively the shorter average $\mathrm{Mn}-\mathrm{N}$ distances, but maintained a long $\mathrm{Mn}-\mathrm{Cl}$ distance (2.40 ̊, Table $\mathrm{S} 2 \dagger)$, in poor agreement

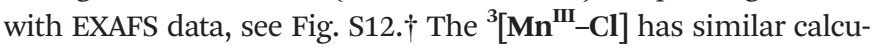
lated average $\mathrm{Mn}-\mathrm{N}$ distances and a much shorter $\mathrm{Mn}-\mathrm{Cl}$ bond length (2.24 A, Table S2 $\dagger$ ) as compared to the quintet, which gives better agreement with EXAFS distances (Fig. 6). However, the fit to the EXAFS spectrum was not significantly improved (Fig. S12 $\dagger$ ). Instead, an alternative quintet structure ${ }^{5}\left[\mathbf{M n}^{\mathrm{III}}-\mathbf{C l}\right]^{\prime}$ with a shorter $\mathrm{Mn}-\mathrm{Cl}$ bond of $2.26 \AA$ (Table 1 and Fig. 6) and elongated bonds in the equatorial plane, lies only $0.6 \mathrm{kcal} \mathrm{mol}^{-1}$ above the most stable quintet and gives a much better fit to EXAFS (Fig. S12†). Considering the small energy difference and the good structural match, this alternative quintet structure will also be considered in further comparisons and analyses.

For [Co $\left.{ }^{\text {III }}-\mathbf{C l}\right]$, EXAFS fitting suggests that upon oxidation the average Co-N distance shortens from $2.14 \AA$ to $1.97 \AA$, and the average $\mathrm{Co}-\mathrm{Cl}$ distance from $2.40 \AA$ to $2.20 \AA$. The majority of

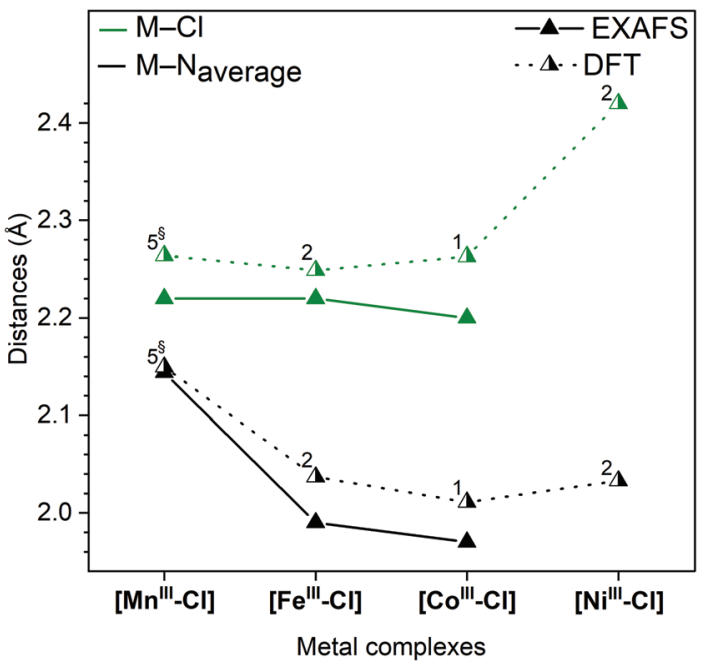

Fig. 6 Metal-ligand distances of the oxidized ${ }^{n}\left[\mathrm{M}^{\prime \prime \prime}-\mathrm{Cl}\right]$ complexes (dissolved in MeCN) obtained by EXAFS spectroscopy at $20 \mathrm{~K}$ (full triangles, solid line) and DFT calculations (half-filled triangles, dotted line). The numbers at the symbols indicate the spin multiplicity of the metal centres. ${ }^{\S}$ Calculated distorted ${ }^{5}\left[\mathrm{Mn}^{\prime \prime \prime}-\mathrm{Cl}\right]$ ' structure.

reported $\mathrm{Co}^{\mathrm{III}}$ complexes exist in a LS singlet configuration, ${ }^{31}$ and the distances found here for $\left[\mathbf{C o}^{\text {III-}}-\mathbf{C l}\right]$ were also consistent with such an assignment. DFT calculations also prefer ${ }^{\mathbf{1}}\left[\mathbf{C o}^{\mathbf{I I I}}-\mathbf{C l}\right]$ over ${ }^{5}\left[\mathrm{Co}^{\mathrm{III}}-\mathbf{C l}\right]$ by a large margin $\left(26.4 \mathrm{kcal} \mathrm{mol}^{-1}\right)$, see Fig. 4 , and ${ }^{3}\left[\mathbf{C o}^{\mathrm{III}}-\mathbf{C l}\right]$ is also much higher in energy, see Table S2. $\dagger$ The calculations reproduce the short metal-ligand bonds of the EXAFS structure, although they are overestimated by approx. $0.04 \AA$.

In contrast to the $\mathrm{Mn}$ and Co complexes, the oxidation of $\left[\mathrm{Fe}^{\mathrm{II}}-\mathbf{C l}\right]$ to $\left[\mathrm{Fe}^{\mathrm{III}}-\mathbf{C l}\right]$ did not lead to a similar shortening of the bonds and connected EXAFS changes. While the EXAFS spectrum of $\left[\mathrm{Fe}^{\mathrm{II}}-\mathbf{C l}\right]$ required three components to be fitted at $20 \mathrm{~K}$, the EXAFS data obtained with the oxidized complex, [Fe $\left.{ }^{\text {III }}-\mathbf{C l}\right]$, could be simulated well with a single species that had a short $\mathrm{Fe}-\mathrm{Cl}$ distance $(2.22 \AA)$ and short average Fe-N distance (1.99 $\AA$ ), see Table 1 . This suggests the oxidation to a $\mathrm{LS}^{2}\left[\mathrm{Fe}^{\mathrm{III}}-\right.$ Cl] structure. Unlike the reduced complexes, there was thus no equilibrium between different spin multiplicities or axial ligands $\left(\mathrm{Cl}^{-} v s\right.$. solvent) after oxidation. Energetically, DFT calculations favour the low-spin over the high-spin ${ }^{6}\left[\mathrm{Fe}^{\mathbf{I I I}}-\mathbf{C l}\right]$ structure by $1.1 \mathrm{kcal} \mathrm{mol}^{-1}$ already at $298 \mathrm{~K}$, and this tendency increases with decreasing temperature (Table S5 $\dagger$ ). The calculated average $\mathrm{Fe}-\mathrm{N}$ bonds $(2.04 \AA)$ in the ${ }^{2}\left[\mathrm{Fe}^{\mathrm{III}}-\mathrm{Cl}\right]$ structure are $0.05 \AA$ longer than predicted by experiment (Fig. 6), but still a much better fit than the $2.17 \AA$ of the average $\mathrm{Fe}-\mathrm{N}$ bond distance obtained for the ${ }^{6}\left[\mathrm{Fe}^{\mathrm{III}}-\mathbf{C l}\right]$ complex, see Table $\mathrm{S} 2 . \dagger$

While no oxidized [ $\mathbf{N i}^{\text {III }}-\mathbf{C l}$ ] suitable for EXAFS analysis could be obtained, DFT calculations indicate a preference for $\mathrm{LS}^{2}\left[\mathbf{N i}^{\mathrm{III}}-\mathbf{C l}\right]$ over the alternative $\mathrm{HS}^{4}\left[\mathbf{N i}^{\mathrm{III}}-\mathbf{C l}\right]$ by $16.7 \mathrm{kcal}$ $\mathrm{mol}^{-1}$, see Fig. 4. The LS structure gave short equatorial Ni-N bonds of $1.99 \AA$, and a much longer axial bond of $2.19 \AA$, for an average $\mathrm{Ni}-\mathrm{N}$ bond of $2.03 \AA$. The calculated $\mathrm{Ni}^{\mathrm{III}}-\mathrm{Cl}$ distance is $2.42 \AA$, see Fig. 6. The HS structure had much longer $\mathrm{Ni}-\mathrm{N}$ distances $(2.15 \AA)$ and a shorter $\mathrm{Ni}-\mathrm{Cl}$ distance $(2.23 \AA)$. 


\subsection{Simulated redox potentials}

Redox potentials of the $\left[\mathbf{M}^{\mathrm{III}}-\mathbf{C l}\right] /\left[\mathbf{M}^{\mathrm{II}}-\mathbf{C l}\right]$ couples were simulated using the optimized DFT structures of reduced and oxidized complexes. Calculations of absolute redox potentials of transition metal complexes often show significant errors, up to $0.5 \mathrm{eV}^{32-37}$ Highly charged complexes are in general challenging due to large absolute solvation effects. ${ }^{38}$ Techniques to reduce errors include explicit modelling of the solvent, ${ }^{39}$ and multi-step calculations to reach a neutral reference complex. ${ }^{40}$ Here, the main target was to obtain relative potentials between structurally similar complexes, rather than absolute values, and thus a standard approach was selected.

The results of our DFT calculations are shown as vertical lines in the CVs plotted in Fig. 5, and are also reported in Table S6. $\dagger$ In agreement with our experiments, the lowest redox potential was found for $\left[\mathbf{C o}^{\mathrm{II}}-\mathbf{C l}\right]$. The theoretical value of $0.18 \mathrm{~V}$, is $+0.10 \mathrm{~V}$ higher than the experimental value $(0.08$ $\mathrm{V})$. This deviation is well within the expected accuracy of the calculations, and is likely due to error cancellation. For [ $\mathrm{Fe}^{\mathrm{II}}-$ $\mathbf{C l}$ ], the calculated value was $0.37 \mathrm{~V}$, which is in even better agreement with the experiment $(0.33 \mathrm{~V})$. Experimentally, $\left[\mathrm{Mn}^{\mathrm{II}}-\mathrm{Cl}\right]$ had a higher redox potential $(0.58 \mathrm{~V})$ than both $\left[\mathrm{Fe}^{\mathrm{II}}-\right.$ $\mathbf{C l}]$ and $\left[\mathrm{Co}^{\mathrm{II}}-\mathbf{C l}\right]$. Calculations with the lowest energy structure, ${ }^{5}\left[\mathrm{Mn}^{\mathrm{III}}-\mathrm{Cl}\right]$, gave a value of $0.34 \mathrm{~V}(-0.24 \mathrm{~V}$ vs. exp.), which placed it at the same level as that of the iron complex. Using the alternative ${ }^{5}\left[\mathbf{M n}^{\mathrm{III}}-\mathbf{C l}\right]^{\prime}$ structure would instead give a redox potential of $0.37 \mathrm{~V}$, which is a minor improvement compared to the experiment. Finally, the calculated redox potential of [ $\left.\mathbf{N i}^{\mathrm{II}}-\mathbf{C l}\right]$ was $1.19 \mathrm{~V}$, much higher than the other complexes, and in excellent agreement with the experiment $(1.17 \mathrm{~V})$.

\subsection{Exchange reactions at the sixth ligand position}

For [ $\left.\mathrm{Fe}^{\mathrm{II}}-\mathbf{C l}\right]$, the changes in EXAFS data when dissolved in acetonitrile, together with the presence of a second oxidation event in the $\mathrm{CV}$, suggested that the $\mathrm{Cl}^{-}$ligand can be exchanged. Therefore, chloride-free iron complexes, where the sixth ligand position was occupied by a solvent molecule, were prepared (Scheme 1). Crystals suitable for XRD diffraction were obtained from a DMF solution, and the crystal structure of [Fe ${ }^{\mathrm{II}}$-DMF] (Fig. S2 $\dagger$ ) showed that the oxygen of the amide group in DMF coordinated to the iron. For this material, the XRD data showed that the average $\mathrm{Fe}-\mathrm{N}$ bond length was, at $150 \mathrm{~K}$, shorter by approximately $0.2 \AA$ than in the $\left[\mathrm{Fe}^{\mathrm{II}}-\mathbf{C l}\right]$ complex discussed above, indicating singlet configuration (Table 1). ${ }^{41}$ DFT calculations of the similar $\left[\mathrm{Fe}^{\mathrm{II}}-\mathbf{M e C N}\right]$ complex gave very good agreement with the experimental (XRD) distances, with a maximum deviation of $0.02 \AA$.

Preparing the chloride-free complex in methanol yielded a solid material where $\mathrm{MeOH}$ is in the apical coordination site. When this product was dissolved in acetonitrile, methanol was replaced by an acetonitrile molecule ([Fe $\left.\left.{ }^{\mathrm{II}}-\mathbf{M e C N}\right]\right)$, as observed in a HR-MS conducted at low ionization energy (Fig. S13†). Taken together, these data suggest that the solvent molecule at the apical coordination site was weakly bound and could be easily exchanged. The EXAFS data of [ $\left.\mathrm{Fe}^{\mathrm{II}}-\mathbf{M e C N}\right]$ shown in Fig. 7 could be fitted using a short metal-nitrogen bond length of $1.98 \AA$ (Table 1), consistent with a LS Fe ${ }^{\mathrm{II}}$ centre. The LS configuration was further supported by a ${ }^{1} \mathrm{H}-\mathrm{NMR}$ spectrum of $\left[\mathrm{Fe}^{\mathrm{II}}-\mathbf{M e C N}\right]$ that showed the presence of a diamagnetic metal complex (Fig. S14 $\dagger$ ). DFT calculations also favoured the LS form (by $3.2 \mathrm{kcal} \mathrm{mol}^{-1}$ ) at $298 \mathrm{~K}$ and gave metal-ligand distances within $0.02 \AA$ of the EXAFS analysis.

In contrast to the cyclic voltammogram of $\left[\mathrm{Fe}^{\mathrm{II}}-\mathrm{Cl}\right]$ in acetonitrile that showed two reversible redox waves $\left(E_{1 / 2}=0.33 \mathrm{~V}\right.$ and $0.83 \mathrm{~V}$ ), the $\mathrm{CV}$ of [ $\left.\mathrm{Fe}^{\mathrm{II}}-\mathbf{M e C N}\right]$ showed only one reversible redox wave with a potential that matched the position of the second wave of the $\mathrm{CV}$ labelled [ $\mathrm{Fe}^{\mathrm{II}}-\mathbf{C l}$ ] (Fig. 5 and $\mathrm{S} 15 \dagger$ ). Fig. 8 shows that addition of $\mathrm{Cl}^{-}$into a solution of $\left[\mathrm{Fe}^{\mathrm{II}}-\right.$ MeCN] in electrolyte led to the appearance of a reversible redox wave at $+0.33 \mathrm{~V}$ that coincided with the first reversible couple of $\left[\mathrm{Fe}^{\mathrm{II}}-\mathrm{Cl}\right]$, suggesting that $\left[\mathrm{Fe}^{\mathrm{II}}-\mathrm{Cl}\right]$ and $\left[\mathrm{Fe}^{\mathrm{II}}-\mathbf{M e C N}\right]$ interchanged easily in solution. An electrochemical contribution to this ligand exchange can be excluded as we observed the same shift in the equilibrium by monitoring the Cl-titration by UV-Vis spectroscopy in pure acetonitrile (Fig. S16 $\dagger$ ). The UV-Vis data obtained in presence of $\mathrm{TBAPF}_{6}$ revealed that the supporting electrolyte partially shifted this equilibrium in favour of the $\left[\mathrm{Fe}^{\mathrm{II}}-\mathbf{M e C N}\right]$ species (Fig. S17 $\dagger$ ). This effect was probably due to the increased ionic strength of the medium, which stabilized free chloride in the solvent. This explains, why even after addition of two equivalents of $\mathrm{Cl}^{-}$a mixture of $\left[\mathrm{Fe}^{\mathrm{II}}-\mathbf{C l}\right]$ and $\left[\mathrm{Fe}^{\mathrm{II}}-\mathbf{M e C N}\right]$ was still observed (Fig. 8 and S16a†). In addition, the $\mathrm{Cl}_{2} / \mathrm{Cl}^{-}$redox couple was also observed at $E_{\mathrm{p}}=0.72 \mathrm{~V}$ in the oxidative scan in Fig. 8 .

In contrast to the $\left[\mathrm{M}^{\mathrm{II}}-\mathbf{C l}\right]$ complexes, the oxidation of the [Fe $\left.{ }^{\mathrm{II}}-\mathrm{MeCN}\right]$ complex occurred without significant structural changes (Fig. 7 and Table 1), although the oxidation was witnessed by the edge shift in the XANES region (Fig. S7†). The near-constant metal-ligand distances (Table 1) suggested a transition between two LS species, i.e. from ${ }^{1}\left[\mathrm{Fe}^{\mathrm{II}}-\mathbf{M e C N}\right]$ to ${ }^{2}\left[\mathrm{Fe}^{\mathrm{III}}-\mathrm{MeCN}\right]$, which was supported by DFT energy and structure calculations (Table S2 $\dagger$ ). DFT calculations of the redox potential of $\left[\mathrm{Fe}^{\mathrm{II}}-\mathbf{M e C N}\right]$ gave a value of $0.76 \mathrm{~V}$, which was in good agreement with the experimental value of $0.83 \mathrm{~V}$ (Fig. S15†).

\subsection{Orbital energetics}

The above experiments and DFT analysis established that the $\mathrm{M}^{\mathrm{II}}$ to $\mathrm{M}^{\mathrm{III}}$ oxidations can be assigned to clean one-electron oxidations with the expected metal-ligand bond shortenings for the Mn- and Co complexes, while a more complex situation was identified for the Fe-complex, where the apical position was exchangeable for $\left[\mathrm{Fe}^{\mathrm{II}}-\mathrm{Cl}\right]$ and different spin states can be stabilized depending on temperature, while only one structure was observed after oxidation to $\mathrm{Fe}^{\mathrm{III}}$. To rationalize these results and the observed spin multiplicities within simple models, we discuss the electronic structure of our complexes using a molecular orbital framework.

The introducing an apical ligand $(\mathrm{X})$ to a hypothetical complex with six equivalent ligands $\left(O_{\mathrm{h}}\right.$ point group) decreases 

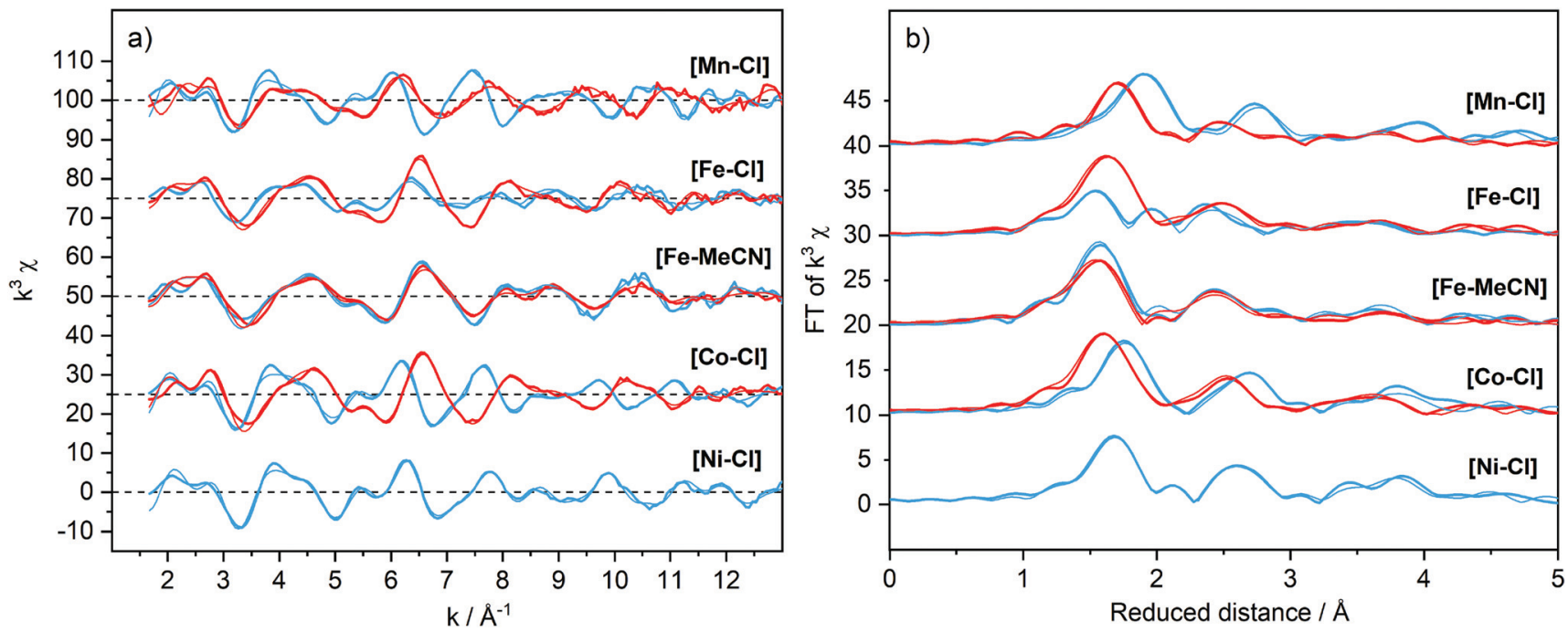

Fig. 7 EXAFS spectra weighted by $k^{3}(\mathrm{a})$ and their Fourier transforms (b) of the $[\mathrm{M}-\mathrm{X}]$ complexes $(1 \mathrm{mM})$ dissolved in acetonitrile with the addition of $\mathrm{TBAPF}_{6}(0.1 \mathrm{M})$. Spectra were recorded at $20 \mathrm{~K}$ and are offset for clarity. Divalent [ $\left.\mathrm{M}^{\prime \prime}-\mathrm{X}\right]$, blue; oxidized [M $\left.{ }^{\prime \prime \prime}-\mathrm{X}\right]$ samples, red. Simulations of the experimental data are shown as thin lines and the parameters are given in Table S4. $\dagger$

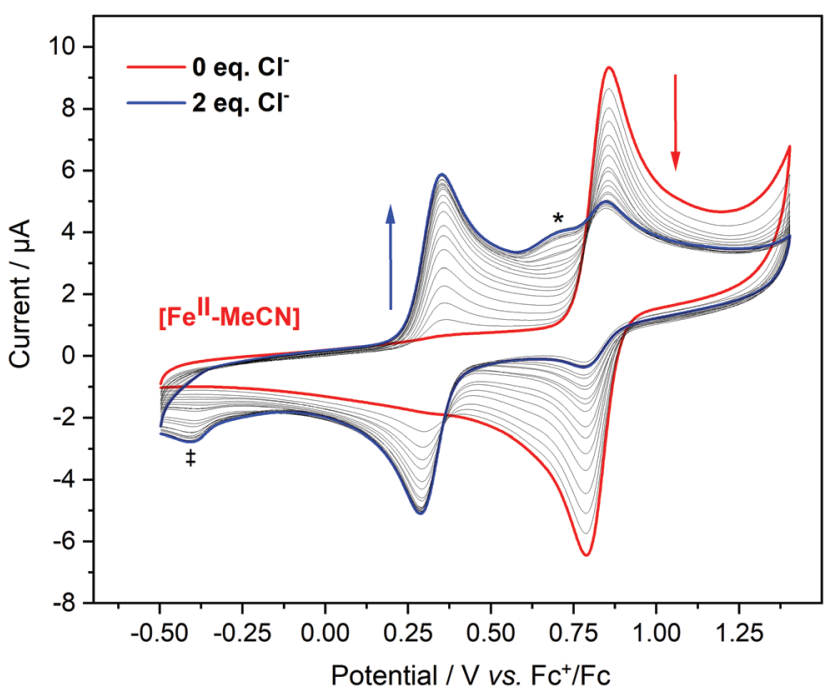

Fig. 8 Cyclic Voltammograms of $\left[\mathrm{Fe}^{\prime \prime}-\mathrm{MeCN}\right](0.5 \mathrm{mM})$ in $0.1 \mathrm{M}$ $\mathrm{TBAPF}_{6}$ in acetonitrile with addition of $0-2$ equivalent (in 0.1 equivalent steps; thin lines) of $\mathrm{Cl}^{-}$(as a MeCN solution of TBACl with $0.1 \mathrm{M} \mathrm{TBAPF}_{6}$ as electrolyte) with respect to the metal complex. Curves were corrected according to the dilution factors. The arrows indicate how the reversible peaks are changing upon the additions. Scan rate, $100 \mathrm{mV} \mathrm{s}^{-1}$. The shoulder at $0.72 \mathrm{~V}$ marked with $(*)$ was assigned to the oxidation of $\mathrm{Cl}^{-}$. The reductive feature at $-0.4 \mathrm{~V}$ marked with $(\grave{\dagger})$ was tentatively assigned to a further reaction between $\mathrm{Cl}_{2}$ and the Fe complex.

its symmetry. As shown by our experiments and DFT calculations, this includes for the $\left[\mathbf{M}^{\mathrm{II}}-\mathbf{C l}\right]$ complexes a displacement of the central metal ion from the equatorial plane along the $C_{4}$-axis. Thus. a $C_{4 \mathrm{v}}$ symmetry is a fair assignment of the local metal environment. In reality, the symmetry deviates from $C_{4 \mathrm{v}}$ to a certain extent since there is no authentic $C_{4}$ rotational axis giving the Py5OH ligand. This deviation, however, does not change the principles in the following section.

The calculated electronic structure of the Py5 complexes are consistent with a previous analysis that described the pyridine rings as being predominantly $\sigma$-donor and $\pi$-acceptor ligands, ${ }^{5}$ while $\mathrm{Cl}^{-}$as $\sigma$ and $\pi$ donor. In a $C_{4 \mathrm{v}}$ symmetry, the orbital degeneracy from the well-known cubic environment is lifted. Consequently, the metal $3 \mathrm{~d}$-dominated $\mathrm{t}_{2 \mathrm{~g}}$ and $\mathrm{e}_{\mathrm{g}}$ orbitals in a virtual $O_{\mathrm{h}}$ symmetry transform to $\mathrm{b}_{2}+\mathrm{e}$ and $\mathrm{a}_{1}+\mathrm{b}_{1}$ respectively, see Fig. 9. The lowest $b_{2}$ level is related to a $d_{x y}$ orbital (equatorial pyridines $\pi$-bonding), above which is two-fold degenerated $\mathrm{e}$ level related to $\mathrm{d}_{x z}$ and $\mathrm{d}_{y z}$ orbitals (pyridine $\pi$-bonding and $\mathrm{Cl}^{-}$ $\pi$-antibonding). These three orbitals will be labelled as $\pi$-type orbitals. Higher in the energy are $a_{1}$ and $b_{1}$ levels, both $\sigma$-type orbitals related to $\mathrm{d}_{z^{2}}\left(\mathrm{Cl}^{-} /\right.$pyridine $\sigma$-antibonding $)$ and $\mathrm{d}_{x^{2}-y^{2}}$ (pyridine $\sigma$-antibonding), respectively. The ordering of these two levels will be discussed in more detail below.

Going from left to right in the periodic table lowers the energy level of the metal orbitals because the additional nuclear charge is only partially screened by the extra electron. This lowering is even more pronounced when increasing the formal oxidation state. For ligand-donor bonding, lowering the metal level leads to smaller energy differences between metal and ligand orbitals, and thus a stronger interaction. For ligand-acceptor binding, it instead leads to a larger energy difference between metal and empty ligand energy levels and weaker interactions. In general, the energy difference between the $\pi$-levels and the antibonding $\sigma$-levels increases, which corresponds to a larger ligand-field splitting. These general principles can now be used to rationalize trends in geometric structure, spin-state energetics, and electrochemical behaviour. 


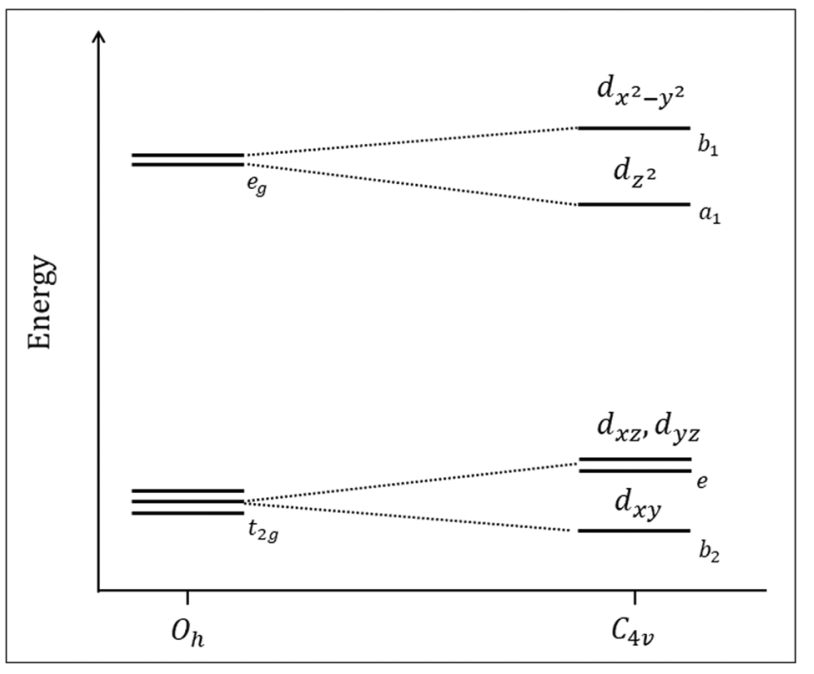

Fig. 9 Schematic orbital energy diagram of the $\left[M^{\prime \prime}-\mathrm{Cl}\right]$ complexes investigated in this study, including a descent in symmetry from a hypothetical complex with six equivalent ligands $\left(O_{\mathrm{h}}\right.$ point group) to local $C_{4 v}$ symmetry at the metal. The relative position of the $d_{x^{2}-y^{2}}$ and $d_{z^{2}}$ orbitals will be discussed further below.

\subsection{Trends in geometric and electronic structure for different metals}

Starting with the geometric structures of the reduced $\left[\mathbf{M}^{\mathbf{I I}}-\mathbf{C l}\right]$ complexes, there is a clear trend of decreasing metal-ligand bond distances from $\mathrm{Mn}$ to $\mathrm{Ni}$, see Fig. 3. This is consistent with a decrease in ionic radius with higher nuclear charge $Z$. However, the change in ionic radius from $\mathrm{Mn}$ to $\mathrm{Ni}$ is only $0.03 \AA$, while the average $\mathrm{M}-\mathrm{N}$ distances decrease by $0.15 \AA$. At the same time, the $\mathrm{M}-\mathrm{Cl}$ distance decreases when going from $\left[\mathbf{M n}^{\text {II }}-\mathbf{C l}\right]$ to $\left[\mathrm{Fe}^{\mathrm{II}}-\mathbf{C l}\right]$, but then increases slightly for later elements. As all reduced complexes are predicted to be HS, the number of electrons in the $\pi$-type orbitals increases from three to six along with the periodic table, while the number of electrons in $\sigma$-type orbitals is constant at two. Going from ${ }^{6}\left[\mathbf{M n}^{\text {II }}\right.$ $\mathbf{C l}$ ], which has one unpaired electron in each $3 \mathrm{~d}$ orbital, to ${ }^{5}\left[\mathbf{F e}^{\mathrm{II}}-\mathbf{C l}\right]$ adds a spin-down electron in the lowest orbital $\mathrm{d}_{x y}$. This orbital is weakly bonding with respect to the equatorial $\mathrm{Fe}-\mathrm{N}$ and the effect of an extra electron is a strengthening of the $\mathrm{Fe}-\mathrm{N}$ bonds and a slight decrease in metal-ligand bond lengths. At the same time, going from $\mathrm{Mn}$ to Fe lowers the energy of the metal 3d orbitals, which leads to stronger $\sigma$ bonding and a reduction in all bond distances. As both effects work in the same direction, all bond distances contract.

The results are more interesting when going from Fe to Co. In ${ }^{4}\left[\mathbf{C o}{ }^{\text {II }}-\mathbf{C l}\right]$ the extra electron goes into the $\mathrm{d}_{x z} / \mathrm{d}_{y z}$ level, which is bonding with respect to the pyridines and antibonding with respect to $\mathrm{Cl}^{-}$. The added electron leads to shorter $\mathrm{M}-\mathrm{N}$ bonds and longer $\mathrm{M}-\mathrm{Cl}$ bonds. At the same time, increased donor bonding should have an overall contracting effect. Still, for the metal-chlorine bond, the anti-bonding effect dominates, and the bond length increases. Finally, going from ${ }^{4}\left[\mathrm{Co}^{\mathrm{II}}-\mathbf{C l}\right]$ to ${ }^{3}\left[\mathrm{Ni}^{\mathrm{II}}-\mathbf{C l}\right]$ puts another electron into the $\mathrm{d}_{x z} / \mathrm{d}_{y z}$ orbitals, which leads to similar changes as seen when going from Fe to Co. The molecular orbital analysis can thus fully explain the bond length trends for the reduced complexes.

The metal-ligand distances of the oxidized complexes show a complex behaviour upon exchange of the metal (Fig. 6). The computational analysis of the [ $\left.\mathbf{M n}^{\text {III-}} \mathbf{- C l}\right]$ compound is complicated because of the deviations between the experiment and the lowest-energy ${ }^{5}\left[\mathbf{M n}{ }^{\text {III-}}-\mathbf{C l}\right]\left(\pi^{3} \sigma^{1}\right)$ structure. The short $\mathrm{Mn}-\mathrm{Cl}$ bond from EXAFS (2.22 $\AA$ ) suggests that an electron is removed from the anti-bonding $\sigma$-type $d_{z^{2}}$ orbital upon oxidation, but the calculations instead give for ${ }^{5}\left[\mathbf{M n}^{\text {III-Cll }}\right.$ a long $\mathrm{Mn}-\mathrm{Cl}$ and shorter $\mathrm{Mn}-\mathrm{N}_{\text {eq. }}$ bonds, see Table $\mathrm{S} 2, \dagger$ consistent with an electron taken from the $d_{x^{2}-y^{2}}$ orbital. The alternative ${ }^{5}\left[\mathbf{M n}{ }^{\text {III-Cl}]^{\prime}}\right.$ structure, which with shorter axial and longer $\mathrm{Mn}-\mathrm{N}_{\mathrm{eq}}$. bonds, gives a better EXAFS match (Fig. 6), is more consistent with an empty $\mathrm{d}_{z^{2}}$ orbital. It is thus possible that the calculations remove the electron from the wrong $\sigma$ orbitals in this oxidation process.

As the octahedral HS $\mathrm{Mn}^{\text {III }}$ complex shows a Jahn-Teller distortion, the difference between the two calculated structures can also be viewed as a change in distortion axis.

As the calculations consistently overestimate the axial Mn$\mathrm{N}$ bond distances, it is possible that they artificially favour the ${ }^{5}\left[\mathbf{M n}^{\text {III-Cl}}\right]$ structure with a Jahn-Teller-like elongation in this direction. Overestimations of the $\mathrm{Mn}^{\mathrm{III}} \mathrm{JT}$ distortion have also been previously observed in DFT calculations. ${ }^{42}$

For ${ }^{2}\left[\mathrm{Fe}^{\mathrm{III}}-\mathbf{C l}\right]$ theory and experiment largely agree, see Fig. 6. The ${ }^{2}\left[\mathrm{Fe}^{\mathrm{III}}-\mathbf{C l}\right]$ complex has a LS $\left(\pi^{5} \sigma^{0}\right)$ electron configuration and compared to ${ }^{5}\left[\mathbf{M n}^{\mathrm{III}}-\mathbf{C l}\right]$ this means extra electrons in $\mathrm{d}_{x y}$ and one of the $\mathrm{d}_{x z}, \mathrm{~d}_{y z}$ orbitals while removing the final $\sigma$ electron. This leads to short axial as well as equatorial bonds. Going further from ${ }^{2}\left[\mathbf{F e}^{\text {III }}-\mathbf{C l}\right]$ to LS $^{1}\left[\mathbf{C o}^{\mathbf{I I I}}-\mathbf{C l}\right]\left(\pi^{6} \sigma^{0}\right)$ adds an electron to $d_{x z} / d_{y z}$, and as these are antibonding with respect to $\mathrm{Cl}^{-}$, together with the general contraction with larger $Z$ there should be small changes in the $\mathrm{M}-\mathrm{Cl}$ distance while the $\mathrm{M}-\mathrm{N}$ distances decrease when going from Fe to Co (Fig. 6). Incidentally, the extra electron is here added to the same orbital level as for the comparison of the reduced iron and cobalt complexes. Finally, the trend when going from ${ }^{1}\left[\mathbf{C o}^{\mathrm{III}}-\mathbf{C l}\right]$ to ${ }^{2}\left[\mathbf{N i}^{\mathrm{III}}-\mathbf{C l}\right]\left(\pi^{6} \sigma^{1}\right)$ can only be derived from calculations as the oxidized nickel complex could not be obtained. They show a significant increase in $\mathrm{M}-\mathrm{Cl}$ bond length and a slight increase in the average $\mathrm{M}-\mathrm{N}$ bond length. The increase in bond distances is expected as the added electron is placed in an $\sigma$ antibonding orbital. As the bond distances increase more along the $C_{4}$-axis, the calculations suggest that the electron ends up in the $\mathrm{d}_{z^{2}}$ rather than the $\mathrm{d}_{x^{2}-y^{2}}$ orbital. LS $\mathrm{Ni}^{\mathrm{III}}$ complex is expected to show a similar Jahn-Teller-like distortion as $\mathrm{HS} \mathrm{Mn}^{\mathrm{III}}$, and the long $\mathrm{M}-\mathrm{Cl}$ distance is similar to that of the ${ }^{5}\left[\mathbf{M n}^{\text {III }}-\mathbf{C l}\right]$ structure. However, as seen from the [ $\mathbf{M n}^{\text {III- }}$ Cl] calculations, it is possible that the structure instead would have a distortion along the equatorial $\mathrm{M}-\mathrm{N}$ plane.

The spin-state energetics are governed by two major factors, the ligand-field strengths and the differences in exchange stabilization between electron configurations. If the former is 
sufficiently large, the benefit of being at the lower orbital levels competes with and overcomes the loss of exchange stabilization and the electrons fill lower $b_{2}$ and e orbitals, resulting in LS configurations. The exception is $\mathrm{Ni}^{\mathrm{II}}$ where both spin configurations have two electrons in the upper two levels. In general, both ligand-field strengths and the exchange interactions increase along the periodic table. However, with changing d-electron count, the difference in the number of ligandfield excitations and exchange interactions change between LS and HS states. The resulting spin-state energetics in Fig. 4, therefore, do not follow any linear trend but are rather consistent with the spectrochemical series of metals.

Taking the reduced complexes as an example, $\left[\mathbf{M n}^{\mathrm{II}}-\mathbf{C l}\right]$, it has a relatively weak ligand field and the sextet has all electrons with the same spin orientation, leading to a highly stable configuration as seen in Fig. 4. Going to $\mathrm{d}^{6} \mathrm{Fe}^{\mathrm{II}}$ and $\mathrm{d}^{7} \mathrm{Co}^{\mathrm{III}}$, all electrons can no longer have the same spin orientation, and the ligand-field splitting increases, resulting in the lower relative stability of the HS configurations. As mentioned above, for $\mathrm{d}^{8}\left[\mathrm{Ni}^{\mathrm{II}}-\mathrm{Cl}\right] \mathrm{b}_{2}$ and e orbitals $\left(\mathrm{b}_{2}{ }^{2} \mathrm{e}^{4}\right)$ are filled in all configurations, and the high spin is favoured because it allows for $a_{1}$ and $b_{1}$ to be half-filled with electrons in the same spinorientation.

\subsection{Trends in redox potential for different metals}

An important target of this study has been to understand the factors that determine the redox potentials of different base metals in the $\mathrm{Py} 5 \mathrm{OH}$ complexes. Starting from a basic atomic picture, the redox potential increases when going from left to right in the periodic table as the energy of the $3 \mathrm{~d}$ levels decrease with increasing nuclear charge. For the Py5OH complexes, the electrochemical experiments instead gave the trend $\mathrm{Co}<\mathrm{Fe}<\mathrm{Mn}<\mathrm{Ni}$. To analyse the effect of the ligand environment, we consider electronic, geometric, and spin degrees of freedom.

From Fig. 5 it is clear that the redox potentials of all complexes except $\left[\mathbf{M n}{ }^{\mathrm{II}}-\mathbf{C l}\right]$ are well described by the calculations, not only in terms of relative but also absolute potentials. The main discrepancy is that manganese is too easy to oxidize according to the calculations. However, the deviation, -0.24 $\mathrm{eV}$, is within the expected accuracy of the method, and the calculations reproduce the overall experimental trend well enough to be used to rationalize the trends in redox potential.

The oxidation process will be analysed in three schematic steps. The first step is the removal of an electron from the highest occupied molecular orbital, which in all cases is the $\sigma$ type $\mathrm{d}_{x^{2}-y^{2}}$ orbital, and the subsequent orbital relaxation. This is followed by geometry relaxation to the minimum energy geometry of the oxidized species. Finally, in cases where a more stable spin multiplicity existed, spin change was allowed.

The description of $\left[\mathbf{M n}^{\mathrm{II}}-\mathbf{C l}\right]$ oxidation is straightforward: removing an electron is equivalent to going from ${ }^{6}\left[\mathrm{Mn}^{\mathrm{II}}-\mathbf{C l}\right]$ $\left(\pi^{3} \sigma^{2}\right)$ to ${ }^{5}\left[\mathbf{M n}{ }^{\mathrm{III}}-\mathbf{C l}\right]\left(\pi^{3} \sigma^{1}\right)$. Including only orbital relaxation would lead to a hypothetical redox potential of $1.11 \mathrm{~V}$, see Fig. 10. This is followed by geometric relaxation of the oxidized complex to its minimum energy, which leads to a drop in the

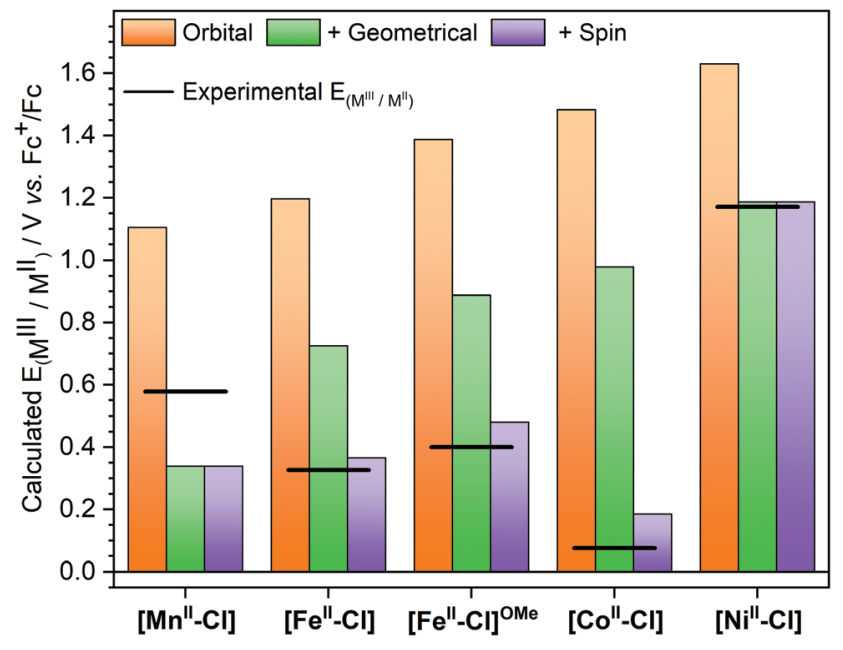

Fig. 10 Theoretically calculated half potentials for the $\left[\mathrm{M}^{\prime \prime \prime}-\mathrm{Cl}\right] /\left[\mathrm{M}^{\prime \prime}-\right.$ $\mathrm{Cl}$ redox couples. Allowing only for orbital relaxation after removal of an electron from the same orbital in all complexes, orange bars; allowing for geometric relaxation, green bars; allowing for spin multiplicity change, purple bars. The experimental redox potentials are shown as a line. $\left[\mathrm{Fe}^{\mathrm{II}}-\mathrm{Cl}\right]^{\mathrm{OMe}}$ represents the $\left[\mathrm{Fe}^{\prime \prime}(\mathrm{Py} 5 \mathrm{OMe}) \mathrm{Cl}^{+}\right.$complex with the experimental value reported by Stack et al. ${ }^{4}$

potential to $0.34 \mathrm{~V}$. As the quintet is also the lowest energy of $\left[\mathrm{Mn}^{\mathrm{III}}-\mathrm{Cl}\right]$, this is also the final calculated redox potential. Using instead the alternative ${ }^{5}\left[\mathbf{M n}^{\mathrm{III}}-\mathbf{C l}\right]^{\prime}$ structure, which would be consistent with the removal of $\mathrm{a}_{z^{2}}$ electron, would give a very similar analysis, although with a slightly higher final potential $(0.37 \mathrm{~V})$. The relative order of $\mathrm{d}_{z^{2}}$ and $\mathrm{d}_{x^{2}-y^{2}}$ might thus not be correctly predicted, but this does not seem to have a significant effect on the analysis.

For $\left[\mathrm{Fe}^{\mathrm{II}}-\mathrm{Cl}\right]$, the oxidation is a ${ }^{5}\left[\mathrm{Fe}^{\mathrm{II}}-\mathrm{Cl}\right]\left(\pi^{4} \sigma^{2}\right)$ to ${ }^{2}\left[\mathrm{Fe}^{\mathrm{III}}-\mathbf{C l}\right]$ $\left(\pi^{5} \sigma^{0}\right)$ transition. Taking an electron from a $\sigma$-type orbital leads initially to a ${ }^{4}\left[\mathrm{Fe}^{\mathrm{III}}-\mathrm{Cl}\right] \pi^{4} \sigma^{1}$ configuration at $1.20 \mathrm{~V}$, which then drops to $0.73 \mathrm{~V}$ upon geometry relaxation, see Fig. 10 . However, for iron, there is an additional change in spin multiplicity from a quartet to a doublet, which gives the final calculated potential of $0.37 \mathrm{~V}$. The analysis for the ${ }^{4}\left[\mathbf{C o}{ }^{\mathrm{II}}-\mathbf{C l}\right]\left(\pi^{5} \sigma^{2}\right)$ to ${ }^{1}\left[\mathbf{C o}^{\mathbf{I I I}}-\mathbf{C l}\right]\left(\pi^{6} \sigma^{0}\right)$ transition is similar to the case for iron. The oxidation to ${ }^{3}\left[\mathbf{C o}^{\mathrm{III}}-\mathbf{C l}\right]\left(\pi^{5} \sigma^{1}\right)$ gives potentials of 1.48 and $0.98 \mathrm{~V}$ after orbital and geometric relaxation, respectively. For [Co ${ }^{\text {III-}}-\mathbf{C l}$ ], the singlet is much more stable than the triplet, which leads to a drop in the potential down to $0.19 \mathrm{~V}$. Finally, for $\left[\mathbf{N i}^{\mathrm{II}}-\mathbf{C l}\right]$ the electron is also taken from a $\sigma$-type orbital as it goes from ${ }^{3}\left[\mathrm{Ni}^{\mathrm{II}}-\mathbf{C l}\right]\left(\pi^{6} \sigma^{2}\right)$ to ${ }^{2}\left[\mathrm{Ni}^{\mathrm{iII}}-\mathbf{C l}\right]\left(\pi^{6} \sigma^{1}\right)$. As expected, the removal of a $\sigma$ electron is more difficult in $\left[\mathrm{Ni}^{\mathrm{II}}-\mathrm{Cl}\right]$ than in the other complexes, leading to a potential of $1.19 \mathrm{~V}$ after geometric relaxation. As there is no further change in spin multiplicity, this is also the final redox potential, which is then much higher than for any other complex in the series. From the trends in Fig. 10 it is thus clear that if only orbital and geometry relaxation would occur, the potentials of all our Py5OH complexes would follow the order in the periodic table, i.e. show a higher redox potentials with higher $Z$. It is thus the difference in energy stabilization from potential changes in 
spin multiplicity that determines the final order of the redox potentials. The calculations can thus be used to rationalize the changes in electrochemical properties between different base metals.

\subsection{Exchange reactions at the sixth ligand position}

Exchange reactions at the sixth ligand position are likely required for the activation of substrates in catalytic reactions involving the $\left[\mathbf{M}^{\mathrm{II}}-\mathbf{C l}\right]$ complexes. From the experimental data, it is clear that $\left[\mathrm{Fe}^{\mathrm{II}}-\mathbf{C l}\right]$ can release $\mathrm{Cl}^{-}$in the electrolyte acetonitrile solution. To get insight into the process, the reaction energy for chloride substitution by the solvent acetonitrile was calculated for the four metal complexes using DFT. The calculations show a trend in $\mathrm{Cl}^{-}$binding energies consistent with the distance analysis (Fig. 11), where binding in $\left[\mathbf{F e}^{\mathbf{I I}}-\mathbf{C l}\right]$ is stronger than in $\left[\mathbf{M n}^{\mathrm{II}}-\mathbf{C l}\right]$ due to the better overlap between metal and ligand donor orbitals. The $\mathrm{Fe}-\mathrm{Cl}$ bond is also stronger than in [Co $\left.{ }^{\text {II }}-\mathbf{C l}\right]$, because the latter has additional electrons in the anti-bonding $\mathrm{d}_{x z} / \mathrm{d}_{y z}$ orbitals as described above. Finally, the binding energy to $\left[\mathbf{N i}^{\mathbf{I I}}-\mathbf{C l}\right]$ is the highest in the series, likely due to further metal-ligand mixing with higher $Z$.

The ligand exchange equilibrium is instead determined by the energy costs for solvating the $\mathrm{Cl}^{-}$ion and the binding energy of the acetonitrile ligand, which binds stronger to Fe and Ni compared to $\mathrm{Mn}$ and Co. Compared to the chloride complex, acetonitrile favours the singlet state by $8.5 \mathrm{kcal}$ $\mathrm{mol}^{-1}$, which makes [Fe $\left.\mathrm{FI}^{\mathrm{II}}-\mathbf{M e C N}\right]$ a low-spin complex.

However, the rest of the $\left[\mathbf{M}^{\mathbf{I I}}-\mathbf{M e C N}\right]$ complexes remain HS, even though the energy difference is only $1.8 \mathrm{kcal} \mathrm{mol}^{-1}$ for [Co'-MeCN]. That means all complexes except iron have electrons in the anti-bonding $\mathrm{d}_{z^{2}}$ orbitals. The reason for stronger bonding in Ni compared to Co could be a combination of improved overlap and the fact that the extra electron now

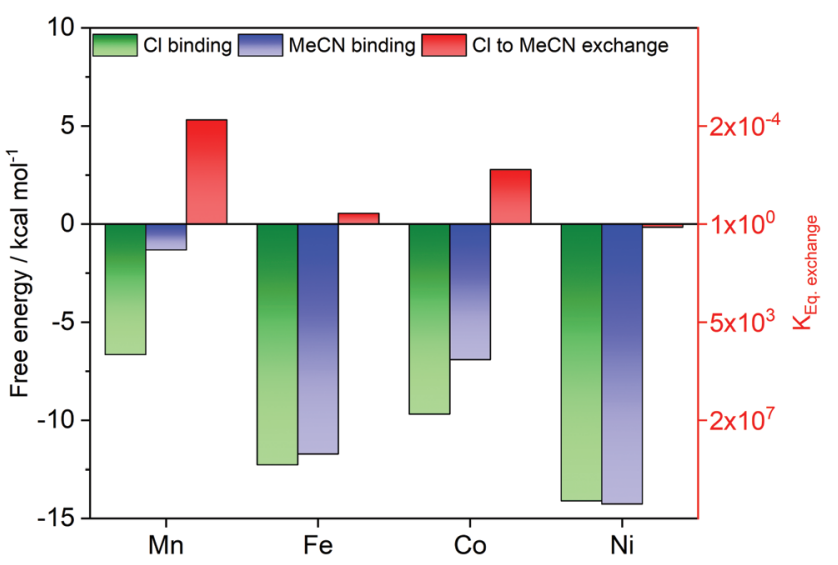

Fig. 11 Calculated ligand binding energies for chloride $\left[\mathrm{M}^{\prime \prime}-\mathrm{Cl}\right]$ (green bars) and acetonitrile [ $\mathrm{M}^{\prime \prime}-\mathrm{MeCN}$ ] (blue bars) complexes in acetonitrile as solvent. The difference in binding energy is the Gibbs free energy required for ligand exchange $\left(\left[\mathrm{M}^{\prime \prime}-\mathrm{Cl}^{+}+\mathrm{MeCN} \rightleftharpoons\left[\mathrm{M}^{\prime \prime}-\mathrm{MeCN}\right]^{2+}+\mathrm{Cl}^{-}\right)\right.$ (red bars; right red axis for the equilibrium constant). All values are calculated at $298 \mathrm{~K}$ with the B3LYP* functional and the SMD solvation model. appears in a $d_{x z} / d_{y z}$ orbital that is bonding between metal and MeCN.

Taken together, the calculations show that the exchange energy, which is the difference between the two binding energies, is close to zero for $\left[\mathbf{F e}^{\mathrm{II}}-\mathbf{C l}\right]$ and $\left[\mathbf{N i}^{\mathbf{I I}}-\mathbf{C l}\right]$, while it is slightly positive for $\left[\mathbf{M n}^{\mathrm{II}}-\mathbf{C l}\right]$ and $\left[\mathbf{C o}^{\mathrm{II}}-\mathbf{C l}\right]$, see Fig. 11. For $\left[\mathbf{M n}^{\text {II }}-\mathbf{C l}\right],\left[\mathbf{F e}^{\text {II }}-\mathbf{C l}\right]$ and $\left[\mathbf{C o}^{\text {II }}-\mathbf{C l}\right]$ this reproduces the trend observed in the experiments, as we observed the exchange of the apical ligand only for the $\left[\mathbf{F e}^{\text {II }}-\mathbf{C l}\right]$ complex. By contrast, for $\left[\mathbf{N i}^{\mathbf{I I}}-\mathbf{C l}\right]$ the thermodynamically expected ligand exchange was not observed, which may indicate a kinetic limitation of this process. Interestingly, for the related $\left[\mathrm{Ni}^{\mathrm{II}}(\mathrm{Py} 5 \mathrm{Me}) \mathrm{Cl}\right]^{+}$ complex the chloride was recently reported to exchange with the solvent. ${ }^{23}$

Calculations of $\left[\mathbf{F e}^{\text {III-}}-\mathbf{C l}\right]$ show that in the oxidized state, the corresponding exchange reaction for a neutral solvent molecule is unfavourable, which is consistent with the EXAFS observations of [Fe $\left.{ }^{\text {III }}-\mathbf{C l}\right]$ described above. The difference in calculated redox potential between $\left[\mathrm{Fe}^{\mathrm{II}}-\mathbf{C l}\right]$ and $\left[\mathrm{Fe}^{\mathrm{II}}-\mathbf{M e C N}\right]$ can also be attributed to the difference in charge, with the anionic ligand favouring lower redox potentials.

\subsection{Effects of Py5 modifications}

The properties of the complexes can be further modified by synthetic changes to the Py5 ligand. Here the focus is on a comparison of the hydroxyl-substituted $\mathrm{Py} 5 \mathrm{OH}$ and previously published results of the methoxy-substituted Py5OMe ligands. The steric hindrance of the methoxy groups in Py5OMe-ligated complexes induces a tilting of the axial pyridine ring relative to the equatorial plane and a nonsymmetrical pyridine coordination in the equatorial plane. ${ }^{15}$ In the case of $\mathrm{Py} 5 \mathrm{OH}$, the perpendicular pyridine is aligned with the axial axis and a less distorted octahedral geometry is observed. We previously calculated that the distortion in Py5OMe leads to a $2.9 \mathrm{kcal} \mathrm{mol}^{-1}$ destabilization of the LS state, ${ }^{15}$ so that $\left[\mathrm{Fe}^{\mathrm{II}}(\mathrm{Py} 5 \mathrm{OMe}) \mathrm{Cl}\right]^{+}$, unlike $\left[\mathrm{Fe}^{\mathrm{II}}(\mathrm{Py} 5 \mathrm{OH}) \mathrm{Cl}\right]^{+}$, stays $\mathrm{HS}$ at all temperatures and does not show a SCO behaviour.

Electrochemically, the Py5OMe complexes have redox potentials that are $0.08 \mathrm{~V}$ higher than the $\mathrm{Py} 5 \mathrm{OH}$ complexes, see Table S6. $\dagger$ The exception is $\mathrm{Ni}$, where the reported redox potential of the Py5OMe complex is $0.78 \mathrm{~V}$ lower. ${ }^{4}$ Based on the good agreement between calculated and measured half potentials for the $\left[\mathbf{N i}^{\mathbf{I I I}}-\mathbf{C l}\right] /\left[\mathbf{N i}^{\mathbf{I I}}-\mathbf{C l}\right]$ redox couple in this study, we assume that the reported values for $\left[\mathrm{Ni}^{\mathrm{iI}}(\mathrm{Py} 5 \mathrm{OMe}) \mathrm{Cl}\right]^{+}$are not reflecting the same redox couple.

To analyse the differences between the two versions of the ligand, the redox potential of the $\left[\mathrm{Fe}^{\mathrm{II}}(\mathrm{Py} 5 \mathrm{OMe}) \mathrm{Cl}\right]^{+}$complex was calculated using the same protocol as for $\left[\mathbf{F e}^{\mathbf{I I}}-\mathbf{C l}\right]$. With this ligand, the ferric complex is also LS, although by a very small margin at $298 \mathrm{~K}\left(0.7 \mathrm{kcal} \mathrm{mol}^{-1}\right)$. The calculated redox potential is $0.11 \mathrm{~V}$ higher than for the [Fe $\mathbf{e}^{\text {II }} \mathbf{C l}$ ] complex, in good agreement with the experimental difference of 0.07 V. Breaking down the process into the different steps shows that the main contribution is the increased energy required to remove the $\sigma$ electron $(+0.18 \mathrm{~V})$, while geometric relaxation and changes in spin multiplicity work in the opposite direc- 
tion ([Fe $\left.{ }^{\mathrm{II}}-\mathbf{C l}\right]^{\mathrm{OMe}}$ in Fig. 10). In the calculations, the electron is taken from the antibonding $\mathrm{d}_{x^{2}-y^{2}}$ orbital, and the structural distortion with the Py5OMe ligand lowers the $\mathrm{d}_{x^{2}-y^{2}}$ level because of poorer overlap. This effect is also visible from the longer equatorial bond distances, by $0.08 \AA$, in $\left[\mathbf{F e}^{\mathrm{II}}-\mathbf{C l}\right]^{\text {OMe }}$. If the observed differences in redox potential could be directly translated into differences in barrier heights, a $0.1 \mathrm{eV}$ difference corresponds to a hundred-fold effect on reaction rates. This shows the potential of modifying Py5 type ligands for tuning the reactivity of these complexes.

\section{Conclusions}

Herein we reported the first comprehensive analysis of the effects of substituting the central base metal, the auxiliary ligand, and distal modification to the ligand framework have been on the redox potential of Py5 coordinated complexes. This analysis was based on a careful structural characterization of both reduced and oxidized species. The trends in structure, spin-state energies, redox potentials, and ligand-exchange reactivity were then rationalized in a molecular orbital picture, supported by DFT calculations. The deviations from a continuous increase in redox potential with increasing nuclear charge were explained by significant stabilization from changes in spin multiplicity for the $\mathrm{Fe}$ and especially Co complexes, leading to large stabilizations of the oxidized states and correspondingly lower redox potentials. Moreover, we demonstrated that the exchange dynamics of the apical ligand, which is observed for Fe in both EXAFS and CV data, can be explained by the favourable binding of the solvent molecule, rather than a weak $\mathrm{Fe}-\mathrm{Cl}$ interaction. Finally, the analysis quantifies the role of Py5 ligand modifications far from the metal site, which had, in line with previously reported spin-state energetics, ${ }^{4,15}$ also measurable effects on the electrochemical behaviour. Thereby, this study shows that even a simple one-electron oxidation reaction can entail unexpected complexity and tunability. Thus, developing efficient and stable multi-electron catalysis with base metals requires a detailed study of all steps of the catalytic cycle. We also demonstrated that DFT calculations could be employed to understand, in most cases, the trends observed. We thus expect that this systematic approach will, in the long run, facilitate deriving design principles allowing the development of efficient and stable catalysts via predictive calculations.

\section{Experimental}

\subsection{Synthesis}

All starting reagents were obtained from commercial sources and used as received. All glassware were cleaned and dried overnight at $120^{\circ} \mathrm{C}$. The synthesis of the metal complexes was conducted under dry Argon atmosphere. The synthesized samples were stored in air without observing any degradation.

The complexes were fully characterized to verify the purity of the desired product by means of ${ }^{1} \mathrm{H}-\mathrm{NMR}$, FT-IR, UV-VIS, HR-MS and elemental analysis as described in the ESI. $\uparrow$ The oxidised metal complexes were obtained by electrolysis in acetonitrile solution $(1 \mathrm{mM})$ as described in the next section.

Caution: Perchlorate salts are potentially explosive and should be handled with care.

$\mathrm{Py} 5 \mathrm{OH}$ was synthesized following a procedure introduced by us recently. ${ }^{15}$ To a dry THF solution (40 ml) of 2,6-dibromopyridine $(0.65 \mathrm{~g}, 2.72 \mathrm{mmol})$ in a $100 \mathrm{ml}$ 3-neck round bottom flask, an excess of $\mathrm{Mg}(0.25 \mathrm{~g}, 102 \mathrm{mmol})$ was added. After sonicating the mixture for 20 minutes at $35^{\circ} \mathrm{C}$ using an ultrasonic bath (45 kHz frequency, model USC300TH, VWR Collection) most of the starting solid $\mathrm{Mg}$ was dissolved and the transparent solution turned dark. A THF solution $(20 \mathrm{ml})$ of di (2-pyridyl)ketone (1.00 g, $5.44 \mathrm{mmol}$ ) was added dropwise to the Grignard reagent with subsequent formation of a white precipitate. The mixture was stirred for 48 hours followed by the addition of $10 \% \mathrm{HCl}(30 \mathrm{~mL})$. The organic solvent was evaporated and the aqueous solution was washed with $\mathrm{CH}_{2} \mathrm{Cl}_{2}$ $(2 \times 50 \mathrm{~mL})$. Neutralization of the aqueous solution with saturated $\mathrm{Na}_{2} \mathrm{CO}_{3}$-solution was followed by extraction with $\mathrm{CH}_{2} \mathrm{Cl}_{2}$ $(3 \times 100 \mathrm{~mL})$. The $\mathrm{CH}_{2} \mathrm{Cl}_{2}$ solvent was evaporated and the

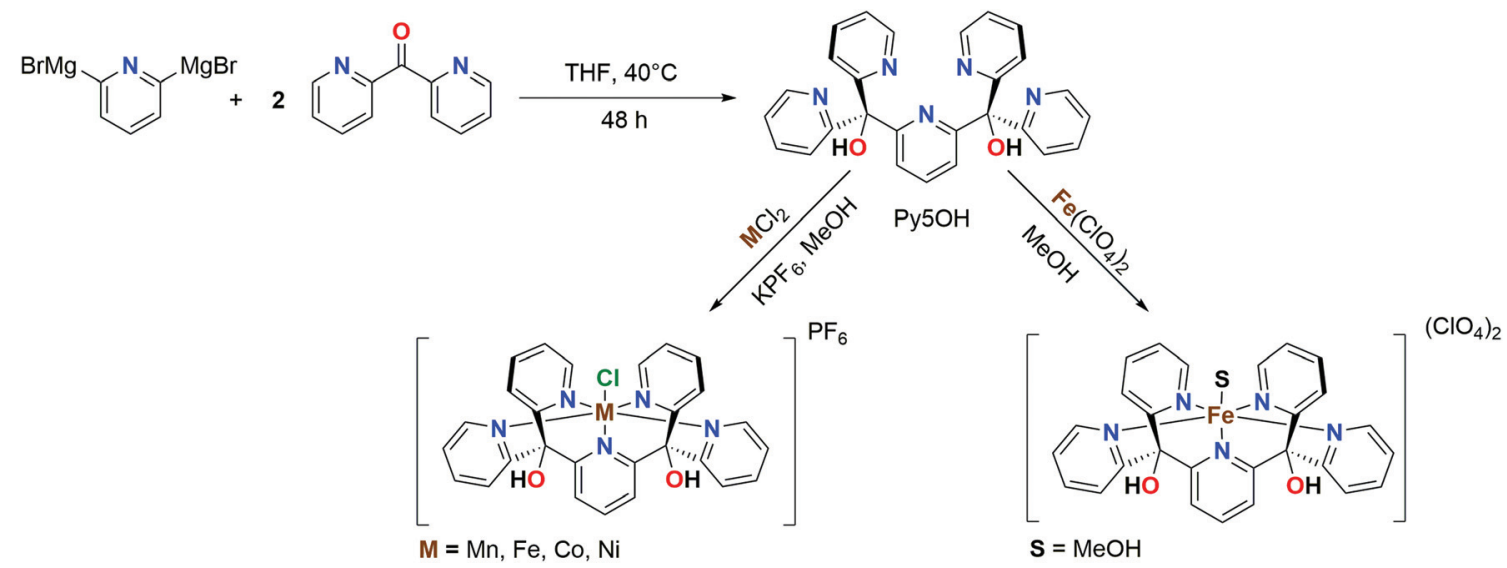

Scheme 1 Synthetic route for the ligand and complexes investigated in this work. 
penta-pyridylcarbinol product was recrystallized from hot acetone (250 mg, $0.558 \mathrm{mmol}$, yield: 10.2\%). ${ }^{1} \mathrm{H}-\mathrm{NMR}$ $\left(400 \mathrm{MHz}, \mathrm{CDCl}_{3}\right): \delta=7.17(4 \mathrm{H}, \mathrm{t}$ of $\mathrm{d}, J 1=5.3 \mathrm{~Hz}, J 2=2.3 \mathrm{~Hz}$, 5-H of Py arms (py-a)), 7.55-7.60 (8 H, m, 3-Нpy-a, 4-Нру-а), 7.71 ( $3 \mathrm{H}, \mathrm{m}, 2-\mathrm{H}$ and $3-\mathrm{H}$ of bridging Py), 8.50 (4 H, m, 6-Hpya) ppm. ${ }^{13} \mathrm{C}-\mathrm{NMR}\left(400 \mathrm{MHz}, \mathrm{CDCl}_{3}\right): \delta=162.1,161.2,147.2$, 137.8, 136.5, 123.5, 122.5, 120.8, 80.9 ppm. MS (+ESI-ToF): $m / z$ : $448.1878\left[\mathrm{Py} 5 \mathrm{OH}+\mathrm{H}^{+}\right]^{+}, 470.1689\left[\mathrm{Py} 5 \mathrm{OH}+\mathrm{Na}^{+}\right]^{+}$.

Elemental analysis. The X-ray spectroscopy and electrochemical data of the $\left[\mathbf{M}^{\mathbf{I I}}-\mathbf{C l}\right]$ and $\left[\mathbf{F e}^{\mathbf{I I}}-\mathbf{M e O H}\right]$ complexes were collected using the powder samples obtained by the synthesis procedures described below, i.e. without any recrystallization step. Below we report the elemental analyses for these powder samples. A fraction of each powder sample was utilized for obtaining the crystals for the single crystal X-ray diffraction structures reported for each complex. The deviations of up to $1.4 \%$ from the calculated values indicate a small level of impurities in the powder samples, which we assign to non-redox active and non-target metal containing species, as no signals were found in the EXAFS, XANES and electrochemical data that could be assigned to impurities.

Synthesis of $\left[\mathbf{M n}^{\mathrm{II}}(\mathbf{P y} \mathbf{5 O H}) \mathbf{C l}\right] \mathbf{P F}_{\mathbf{6}}\left(\left[\mathbf{M n}^{\mathrm{II}}-\mathbf{C l}\right]\right)$. All the reagents were kept under vacuum $\left(5 \times 10^{-4}\right.$ bar $)$ for 2 hours before use. The Py5OH ligand $(149.0 \mathrm{mg}, 0.33 \mathrm{mmol})$ was dissolved in $25 \mathrm{~mL}$ of dry oxygen-free methanol in a $50 \mathrm{~mL}$ Schlenk flask. Subsequently, $\mathrm{MnCl}_{2}$ (47.0 mg, $0.37 \mathrm{mmol}$, purity $98 \%$ ) was introduced to the Schlenk flask under Argon counterflow. After 10 minutes, an excess of $\mathrm{KPF}_{6}(150 \mathrm{mg}, 0.81 \mathrm{mmol})$ was added, and after one hour of constant stirring a white precipitate started to appear. The solid was collected by a rapid Buckner filtration under open air, washed with approx. $4 \mathrm{ml}$ of a cold mixture of methanol and water $(4: 1)$ and kept under vacuum overnight (112.4 mg, $0.16 \mathrm{mmol}$, yield: 49.4\%). High Resolution ESI-MS shows two main molecular fragments at $537.07329 \mathrm{~m} / \mathrm{z}, \quad\left[\mathrm{Mn}^{\mathrm{II}}(\mathrm{Py} 5 \mathrm{OH}) \mathrm{Cl}\right]^{+}$and $501.10787 \mathrm{~m} / \mathrm{z}$ $\left[\mathrm{Mn}^{\mathrm{II}}(\mathrm{Py} 5 \mathrm{OH})-\mathrm{H}^{+}\right]^{+}$. The UV-Vis spectrum presents a strong absorption below $300 \mathrm{~nm}$ with a shoulder at $325 \mathrm{~nm}(\varepsilon=0.76$ $\left.\times 10^{3} \mathrm{M}^{-1} \mathrm{~cm}^{-1}\right)$, see Fig. S15. $\uparrow$ Solid FT-IR $(\mathrm{KBr})$ of the complex shows the same vibration modes as the ligand with a blueshift of $7 \mathrm{~cm}^{-1}$ and the characteristic P-F stretching at $842 \mathrm{~cm}^{-1}$ from the $\mathrm{PF}_{6}{ }^{-}$ion. ${ }^{43} \mathrm{MnC}_{27} \mathrm{H}_{21} \mathrm{~N}_{5} \mathrm{ClO}_{2} \mathrm{PF}_{6}$ (682.85 $\mathrm{g}$ $\mathrm{mol}^{-1}$ ) calcd C 47.49, H 3.10, N 10.26, Cl 5.19; found C 46.76, H 4.37, N 10.41, Cl 5.14.

Synthesis of $\left[\mathrm{Fe}^{\mathrm{II}}(\mathrm{Py} 5 \mathrm{OH}) \mathbf{C l}\right] \mathbf{P F}_{\mathbf{6}}\left(\left[\mathrm{Fe}^{\mathrm{II}}-\mathrm{Cl}\right]\right)$. The synthesis followed the same procedure as above. $\mathrm{FeCl}_{2}(58.0 \mathrm{mg}$, $0.46 \mathrm{mmol}$, purity $98 \%$ ) was used as starting material and after the synthesis, a yellow powder was collected as the product (140.8 $\mathrm{mg}$, $0.21 \mathrm{mmol}$, yield: 46.8\%). High resolution ESI-MS shows two main molecular fragments at $538.06897 \mathrm{~m} / \mathrm{z}$, $\left[\mathrm{Fe}^{\mathrm{II}}(\mathrm{Py} 5 \mathrm{OH}) \mathrm{Cl}\right]^{+}$and $502.10164 \mathrm{~m} / z,\left[\mathrm{Fe}^{\mathrm{II}}(\mathrm{Py} 5 \mathrm{OH})-\mathrm{H}^{+}\right]^{+}$. UV Vis spectrum shows a strong sharp peak at $256 \mathrm{~nm}(\varepsilon=19.24 \times$ $10^{3} \mathrm{M}^{-1} \mathrm{~cm}^{-1}$ ) and a broad absorption at 300-450 $\mathrm{nm}$ with two main maxima at $410 \mathrm{~nm}\left(\varepsilon=2.54 \times 10^{3} \mathrm{M}^{-1} \mathrm{~cm}^{-1}\right)$ and $335 \mathrm{~nm}$ $\left(\varepsilon=2.10 \times 10^{3} \mathrm{M}^{-1} \mathrm{~cm}^{-1}\right.$ ), see Fig. S15. $\dagger$ Solid FT-IR (KBr) of the complex shows the same vibration modes as the ligand with a blueshift of $6 \mathrm{~cm}^{-1}$ and the characteristic P-F stretching at $842 \mathrm{~cm}^{-1}$ from the $\mathrm{PF}_{6}{ }^{-}$ion. ${ }^{43} \mathrm{FeC}_{27} \mathrm{H}_{21} \mathrm{~N}_{5} \mathrm{ClO}_{2} \mathrm{PF}_{6}$ (683.75 $\mathrm{g}$ $\mathrm{mol}^{-1}$ ) calcd C 47.43, H 3.10, N 10.24, Cl 5.19; found C 46.39, H 3.40, N 10.24, Cl 5.12.

Synthesis of $\left[\mathbf{C o}^{\mathrm{II}}(\mathbf{P y} 5 \mathrm{OH}) \mathbf{C l}\right] \mathbf{P F}_{\mathbf{6}}\left(\left[\mathrm{Co}^{\mathrm{II}}-\mathbf{C l}\right]\right)$. The synthesis was similar to that of $\left[\mathbf{M n}^{\mathrm{II}}-\mathbf{C l}\right] \cdot \mathrm{CoCl}_{2}(62.1 \mathrm{mg})$ was used as starting material and a pink product was collected $(193.1 \mathrm{mg}$, yield: $58.7 \%)$.

High Resolution ESI-MS shows two main molecular fragments at $541.08128 \mathrm{~m} / \mathrm{z},\left[\mathrm{Co}^{\mathrm{II}}(\mathrm{Py} 5 \mathrm{OH}) \mathrm{Cl}\right]^{+}$and $505.10374 \mathrm{~m} / \mathrm{z}$, $\left[\mathrm{Co}^{\mathrm{II}}(\mathrm{Py} 5 \mathrm{OH})-\mathrm{H}^{+}\right]^{+}$. The UV-Vis spectrum shows a strong absorption below $400 \mathrm{~nm}$ and a weak broad composite band between $425 \mathrm{~nm}$ and $550 \mathrm{~nm}\left(\varepsilon_{460}=0.04 \times 10^{3} \mathrm{M}^{-1} \mathrm{~cm}^{-1}\right)$, see Fig. S15. $\dagger$ Solid FT-IR $(\mathrm{KBr})$ of the complex shows the same vibration modes as the ligand with a blueshift of $5 \mathrm{~cm}^{-1}$ and the characteristic $\mathrm{P}-\mathrm{F}$ stretching at $842 \mathrm{~cm}^{-1}$ from the $\mathrm{PF}_{6}{ }^{-}$ ion. ${ }^{43} \mathrm{CoC}_{27} \mathrm{H}_{21} \mathrm{~N}_{5} \mathrm{ClO}_{2} \mathrm{PF}_{6}\left(686.84 \mathrm{~g} \mathrm{~mol}^{-1}\right.$ ) calcd $\mathrm{C} 47.21, \mathrm{H}$ 3.08, N 10.20; found C 48.64, H 4.16, N 10.43.

Synthesis of $\left[\mathrm{Ni}^{\mathrm{II}}(\mathrm{Py} 5 \mathrm{OH}) \mathbf{C l}\right] \mathbf{P F}_{\mathbf{6}} \cdot \mathbf{4} \mathrm{H}_{2} \mathrm{O}\left(\left[\mathrm{Ni}^{\mathrm{II}}-\mathrm{Cl}\right]\right)$. The synthesis was similar to the procedure described above. $\mathrm{NiCl}_{2}$ (28.8 $\mathrm{mg}$ ) was used as starting material and after the synthesis, a pale purple powder was collected as the product $(86.0 \mathrm{mg}$, yield: $56.4 \%$ ). High-Resolution ESI-MS shows two main molecular fragments at $540.07372 \mathrm{~m} / z, \quad\left[\mathrm{Ni}^{\mathrm{II}}(\mathrm{Py} 5 \mathrm{OH}) \mathrm{Cl}\right]^{+}$and $504.10734 \mathrm{~m} / \mathrm{z},\left[\mathrm{Ni}^{\mathrm{II}}(\mathrm{Py} 5 \mathrm{OH})-\mathrm{H}^{+}\right]^{+}$.

The UV-Vis spectrum shows a strong absorption below $300 \mathrm{~nm}$ with a shoulder at $320 \mathrm{~nm}\left(\varepsilon=0.75 \times 10^{3} \mathrm{M}^{-1} \mathrm{~cm}^{-1}\right)$, see Fig. S15. $\uparrow$ Solid FT-IR (KBr) of the complex shows the same vibration modes as the ligand with a blueshift of $4 \mathrm{~cm}^{-1}$ and the characteristic $\mathrm{P}-\mathrm{F}$ stretching at $842 \mathrm{~cm}^{-1}$ from the $\mathrm{PF}_{6}{ }^{-}$ ion. ${ }^{43} \mathrm{NiC}_{27} \mathrm{H}_{21} \mathrm{~N}_{5} \mathrm{ClO}_{2} \mathrm{PF}_{6} \cdot 4 \mathrm{H}_{2} \mathrm{O}$ (758.66 $\mathrm{g} \mathrm{mol}^{-1}$ ) calcd $\mathrm{C}$ 42.75, H 3.85, N 9.23, Cl 4.67; found C 42.55, H 3.90, N 9.23, Cl 4.91.

Synthesis of $\left[\mathrm{Fe}^{\mathrm{II}}(\mathrm{Py} 5 \mathrm{OH}) \mathrm{MeOH}\right]\left(\mathrm{ClO}_{4}\right)_{2}\left(\left[\mathrm{Fe}^{\mathrm{II}}-\mathrm{MeOH}\right]\right)$. Dry $\mathrm{Fe}\left(\mathrm{ClO}_{4}\right)_{2}(40 \mathrm{mg}, 157 \mu \mathrm{mol})$ was dissolved in methanol $(2 \mathrm{~mL})$ and added to an argon saturated solution of Py5OH $(52.2 \mathrm{mg}$, $117 \mu \mathrm{mol})$ in methanol $(15 \mathrm{~mL})$. The reaction mixture turned quickly from pale yellow ( $\mathrm{Py} 5 \mathrm{OH}$ colour) to dark orange. The solution was stirred for $4 \mathrm{~h}$ at room temperature and the organic solvent evaporated. The solid was then dissolved in a methanol-ethyl acetate mixture in order to obtain clean crystals. The product was collected and dried overnight under vacuum (yield: $20 \mathrm{mg}, 27 \mu \mathrm{mol}$, yield: $23 \%$ ). High Resolution ESI-MS shows two molecular fragments at $602.04018 \mathrm{~m} / \mathrm{z}$ $\left[\mathrm{Fe}^{\mathrm{II}}(\mathrm{Py} 5 \mathrm{OH})\left(\mathrm{ClO}_{4}\right)\right]^{+}$and $502.0997 \mathrm{~m} / z,\left[\mathrm{Fe}^{\mathrm{II}}(\mathrm{Py} 5 \mathrm{OH})-\mathrm{H}^{+}\right]^{+}$.

$\mathrm{FeC}_{28} \mathrm{H}_{25} \mathrm{~N}_{5} \mathrm{Cl}_{2} \mathrm{O}_{11}\left(734.28 \mathrm{~g} \mathrm{~mol}^{-1}\right)$ calcd C $45.80, \mathrm{H} \mathrm{3.43,} \mathrm{N}$ 9.54; found C 46.3, $\mathrm{H} 4.30, \mathrm{~N} 10.98$.

UV-vis of $\left[\mathrm{Fe}^{\mathrm{II}}(\mathrm{Py} 5 \mathrm{OH}) \mathrm{MeCN}\right]\left(\mathrm{ClO}_{4}\right)_{2} \quad\left(\left[\mathrm{Fe}^{\mathrm{II}}-\mathrm{MeCN}\right]\right)$. $\left[\mathrm{Fe}^{\mathrm{II}}(\mathrm{Py} 5 \mathrm{OH}) \mathrm{MeOH}\right]\left(\mathrm{ClO}_{4}\right)_{2}$ was dissolved in MeCN leading to an immediate exchange of the $\mathrm{MeOH}$ ligand for $\mathrm{MeCN}$. The UV-Vis spectrum of the solution is composed by a broad and weak band at $537 \mathrm{~nm}\left(\varepsilon=0.10 \times 10^{3} \mathrm{M}^{-1} \mathrm{~cm}^{-1}\right)$, a composite region between 300 and $474 \mathrm{~nm}$ with 3 overlapping peaks at 417, 387 and $350 \mathrm{~nm},\left(\varepsilon_{417}=6.535 \times 10^{3} \mathrm{M}^{-1} \mathrm{~cm}^{-1}, \varepsilon_{387}=\right.$ $5.785 \times 10^{3} \mathrm{M}^{-1} \mathrm{~cm}^{-1}$ and $\left.\varepsilon_{350}=5.700 \times 10^{3} \mathrm{M}^{-1} \mathrm{~cm}^{-1}\right)$ and a strong peak at $250 \mathrm{~nm}\left(\varepsilon=20.000 \times 10^{3} \mathrm{M}^{-1} \mathrm{~cm}^{-1}\right)$, see Fig. S15. $\dagger$ 


\subsection{X-ray diffraction}

Single crystals suitable for measurements were obtained for all four $\left[\mathbf{M}^{\mathbf{I I}}-\mathbf{C l}\right]$ complexes and the $\left[\mathbf{F e}^{\mathbf{I I}}-\mathbf{D M F}\right]$ complex by slow diffusion of toluene into a dimethylformamide (DMF) solution of the complex. All the measurements were performed using graphite-monochromatized Mo $\mathrm{K} \alpha$ radiation at $150 \mathrm{~K}$ using a Bruker D8 APEX-II equipped with a CCD camera. Data reduction was performed with SAINT. ${ }^{44}$ Absorption corrections for the area detector were performed using SADABS. ${ }^{45,46}$ The structure was solved by direct methods and refined by fullmatrix least-squares techniques against $F^{2}$ using all data (SHELX). ${ }^{45,46}$ All non-hydrogen atoms were refined with anisotropic displacement parameters if not stated otherwise. Hydrogen atoms were constrained in geometric positions to their parent atoms. The structures were refined using the OLEX2 suite of programs. ${ }^{47}$ See Table $\mathrm{S} 1 \dagger$ for the detailed parameters.

\subsection{X-ray absorption spectroscopy}

$\mathrm{X}$-ray absorption spectroscopy measurements were performed at the KMC-3 beamline at the BESSY II synchrotron facility in Berlin, Germany. The incident X-ray energy was scanned through the Mn, Fe, Co, and Ni K-edge regions using a silicon (111) double-crystal monochromator. Measurements were performed with samples positioned at $45^{\circ}$ with respect to the incident beam in a liquid helium-cooled cryostat (Oxford Instruments). Samples in powder form were mixed with boron nitride in a weight ratio of $1: 30$. Solution samples of the complexes $(1 \mathrm{mM})$ were prepared in dry acetonitrile. A $10 \mu \mathrm{m} \mathrm{Fe}$, $\mathrm{Co}$, or $\mathrm{Ni}$ foil (Goodfellow Cambridge Limited) positioned behind the sample served as an energy calibration standard. For $\mathrm{Mn}$, a thin layer of $\mathrm{KMnO}_{4}$ was used. Energy calibration was done by assigning the position of the maximum of the first derivative of the absorption of the Fe, Co, and Ni foils to energies $7112 \mathrm{eV}, 7709 \mathrm{eV}$, and $8333 \mathrm{eV}$, respectively. The position of the $\mathrm{KMnO}_{4}$ pre-edge was set to $6543.3 \mathrm{eV}$. K $\alpha$ fluorescence signals from the samples were recorded with a 13-element silicon drift detector (RaySpec) positioned perpendicular to the incident beam. For each sample, 8-16 scans were taken in the energy range from $120 \mathrm{eV}$ before the corresponding K-edge up to $750 \mathrm{eV}$ after the edge. Each scan was collected on a new sample spot, to avoid possible radiation damage; additionally, three consecutive scans at the same sample spot confirmed that there was no observable radiation damage on the time scale of the XAS measurement. $E_{0}$ used for EXAFS extraction was $6539 \mathrm{eV}(\mathrm{Mn}), 7115 \mathrm{eV}$ (Fe), $7710 \mathrm{eV}$ (Co) and $8334 \mathrm{eV}(\mathrm{Ni})$. EXAFS simulations were done with the FEFF 9.0 software $^{48}$ (using settings NLEG 6, CRITERIA 125 , RPATH 7, SCF 71300.05 ). The amplitude reduction factor $S_{0}{ }^{2}$ was 0.90 for $\mathrm{Mn}$, Co and $\mathrm{Ni}$, and 0.85 for $\mathrm{Fe}$. Least-squares fitting of $k^{3}$-weighted EXAFS data by changing of interatomic distances for the first four single-scattering shells and DebyeWaller factors for all shells (with all multiple-scattering shells having the same Debye-Waller factor) was done with in-house software (SimXLite). The $k^{3}$-weighted EXAFS data were fitted between $k=1.6 \AA^{-1}$ and $13 \AA^{-1}$. Fit parameter errors were determined as described previously. ${ }^{49}$

\subsection{Bulk electrolysis}

The solution samples of the reduced complexes $(1 \mathrm{mM})$ in 0.1 $\mathrm{M} \mathrm{TBAPF}_{6}$ acetonitrile were oxidized employing a custommade continuous flow electrosynthesis cell. ${ }^{50}$ The applied potential was selected by recording a slow $\left(10 \mathrm{mV} \mathrm{s}^{-1}\right)$ cyclic voltammogram in steady condition. The extent of electrolysis was monitored by recording the current response (typically

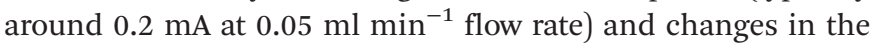
UV-Vis spectrum to provide an estimation of the percentage of the conversion. The oxidized sample solution was collected and frozen in liquid nitrogen for XAS measurements.

\subsection{Cyclic voltammetry}

All solvents, chemicals, glassware, and electrochemical tools were carefully dried. A pseudo reference electrode that consisted of a $\mathrm{AgCl}$ coated $\mathrm{Ag}$ wire immersed in a $0.1 \mathrm{M} \mathrm{TBAPF}_{6}$ acetonitrile solution contained in a porous glass tipped tube was employed. The electrochemical stability of the Ag pseudo reference electrode was tested over 2 days by recording the cyclic voltammetry of ferrocene. A drift of $0.014 \mathrm{~V}$ was observed in the redox potential $\left(E_{1 / 2}\left(\mathrm{Fc}^{+} / \mathrm{Fc}\right)=0.47 \mathrm{~V} v s\right.$. $\mathrm{Ag}$ pseudo reference, in $\mathrm{MeCN})$. All potentials quoted in this study are relative to the $\mathrm{Fc}^{+} / \mathrm{Fc}$ couple.

The glassy carbon working electrode ( $3 \mathrm{~mm}$ diameter) was polished with alumina particles $(0.05 \mu \mathrm{m})$ immediately prior use. The counter electrode was a platinum rod polished with sandpaper before use. Unless stated otherwise, the following parameters were used to record cyclic voltammetry on our samples: scan rate: $100 \mathrm{mV} \mathrm{s}^{-1}$, step potential $0.002 \mathrm{~V}$. The sample concentration was $0.5 \mathrm{mM}$ with tetrabutylammonium hexafluorophosphate supporting electrolyte $(100 \mathrm{mM})$ in acetonitrile.

\subsection{Density-functional theory}

Density-functional theory (DFT) calculations were performed using Gaussian09 E.01. ${ }^{51}$ Initial geometry optimization for all complexes was performed using the B3LYP functional with the Lanl2DZ basis set for transition metals, and 6-31G(p,d) for all other atoms. Thermal contributions were calculated from the subsequent Hessian calculations. Structures were then reoptimized using the B3LYP-D3 functional with the larger Lanl2TZ (f) basis set for the transition metals, and 6-311+G(2df,2pd) for all other atoms. All optimizations were performed in acetonitrile solvent using the default Polarizable Continuum Model (PCM) in Gaussian09. Final energies were calculated with the B3LYP* $^{*}$ functional, ${ }^{52}$ using the D3 parameters from B3LYP. ${ }^{53}$ This functional was previously shown to give good results for spin-state energetics in the spin-crossover complex $\left[\mathbf{F e}^{\mathbf{I I}}-\mathbf{C l}\right] .^{15}$ Final energy calculations are done using the Solvation Model based on Density (SMD). This model gives good absolute solvation energies, which is important for the calculation of half potentials. ${ }^{54}$ Binding energies are calculated from the reaction $\left[\mathbf{M}^{\mathrm{II}}\right]+\mathbf{X} \rightleftharpoons\left[\mathbf{M}^{\mathbf{I I}}-\mathbf{X}\right]$ with all components in acetonitrile solvent, 
including the apical ligand $\mathrm{X}$. For reactions with differences in concentration between components, a configurational entropy factor has been added according to Boltzmann's formula, $S=$ $k_{\mathrm{B}} \ln W$, where $k_{\mathrm{B}}$ is Boltzmann's constant and $W$ is the number of solvent molecules per complex.

Calculated redox potentials are obtained using the reaction $\left[\mathbf{M}^{\mathrm{II}}-\mathbf{X}\right] \rightleftharpoons\left[\mathbf{M}^{\mathrm{III}}-\mathbf{X}\right]+\mathrm{e}^{-}$. The energy of the solvated electron was calculated using $4.28 \mathrm{~V}$ for the absolute potential of the standard hydrogen electrode (SHE). ${ }^{55}$ The choice of reference value affects the absolute potentials, but not the comparison between complexes. Calculated values are given in $\mathrm{V} v s . \mathrm{Fc}^{+} / \mathrm{Fc}$ for comparison with experimental results, with $0.40 \mathrm{~V}$ for the $E_{1 / 2}$ of $\mathrm{Fc}^{+} / \mathrm{Fc} v s$. the SHE. ${ }^{56}$ The analysis of the different contributions to the redox potential was made by separating the calculations of the oxidized species into three steps. First, the energy for removing a spin-up $\sigma$ electron was calculated using the structure of the reduced complex (orbital contribution). Second, the structure was optimized using the same spin multiplicity (geometric). Finally, the energy of the most stable spin multiplicity was calculated (spin).

\section{Conflicts of interest}

There are no conflicts to declare.

\section{Acknowledgements}

This work was supported by the Swedish Energy Agency through grant No. 45421-1. The authors thank the HelmholtzZentrum Berlin (HZB) for the allocation of synchrotron radiation beamtime at the KMC-3 beamline (BESSY II synchrotron, Berlin Adlershof). Calculations were performed on resources provided by SNIC through the National Supercomputer Centre at Linköping University (Tetralith) under projects snic2018-3575 and snic2019-3-498. SIS thanks the ÅForsk Foundation for support (grant No. 19-349). AT and MKH thank the Olle Engkvist Foundation for support (grant number 198-0369).

\section{Notes and references}

1 K. D. Vogiatzis, M. V. Polynski, J. K. Kirkland, J. Townsend, A. Hashemi, C. Liu and E. A. Pidko, Chem. Rev., 2019, 119, 2453-2523.

2 D. J. Durand and N. Fey, Chem. Rev., 2019, 119, 6561-6594.

3 N. Elgrishi, M. B. Chambers, V. Artero and M. Fontecave, Phys. Chem. Chem. Phys., 2014, 16, 13635-13644.

4 R. J. M. Klein Gebbink, R. T. Jonas, C. R. Goldsmith and T. D. P. Stack, Inorg. Chem., 2002, 41, 4633-4641.

5 E. G. Pavel, N. Kitajima and E. I. Solomon, J. Am. Chem. Soc., 1998, 120, 3949-3962.

6 M. E. de Vries, R. M. La Crois, G. Roelfes, H. Kooijman, A. L. Spek, R. Hage and B. L. Feringa, ChemComm, 1997, 1549-1550.
7 R. T. Jonas and T. D. P. Stack, J. Am. Chem. Soc., 1997, 119, 8566-8567.

8 C. R. Goldsmith, R. T. Jonas and T. D. P. Stack, J. Am. Chem. Soc., 2002, 124, 83-96.

9 C. R. Goldsmith, A. P. Cole and T. D. P. Stack, J. Am. Chem. Soc., 2005, 127, 9904-9912.

10 E. L.-M. Wong, G.-S. Fang, C.-M. Che and N. Zhu, ChemComm, 2005, 4578-4580.

11 W.-L. Kwong, C.-N. Lok, C.-W. Tse, E. L.-M. Wong and C.-M. Che, Chem. - Eur. J., 2015, 21, 3062-3072.

12 M. K. Kashif, J. C. Axelson, N. W. Duffy, C. M. Forsyth, C. J. Chang, J. R. Long, L. Spiccia and U. Bach, J. Am. Chem. Soc., 2012, 134, 16646-16653.

13 J. Baillargeon, Y. Xie, A. L. Raithel, B. Ghaffari, R. J. Staples and T. W. Hamann, Inorg. Chem., 2018, 57, 11633-11645.

14 B. Bechlars, D. M. D’Alessandro, D. M. Jenkins, A. T. Iavarone, S. D. Glover, C. P. Kubiak and J. R. Long, Nat. Chem., 2010, 2, 362-368.

15 M. Boniolo, S. I. Shylin, P. Chernev, M. H. Cheah, P. A. Heizmann, P. Huang, N. Salhi, K. Hossain, A. Thapper, M. Lundberg and J. Messinger, ChemComm, 2020, 56, 2703-2706.

16 D. J. Rudd, C. R. Goldsmith, A. P. Cole, T. D. P. Stack, K. O. Hodgson and B. Hedman, Inorg. Chem., 2005, 44, 1221-1229.

17 E. J. Sundstrom, X. Yang, V. S. Thoi, H. I. Karunadasa, C. J. Chang, J. R. Long and M. Head-Gordon, J. Am. Chem. Soc., 2012, 134, 5233-5242.

18 A. E. King, Y. Surendranath, N. A. Piro, J. P. Bigi, J. R. Long and C. J. Chang, Chem. Sci., 2013, 4, 1578-1587.

19 E. Deponti, A. Luisa, M. Natali, E. Iengo and F. Scandola, Dalton Trans., 2014, 43, 16345-16353.

20 Y. Sun, J. P. Bigi, N. A. Piro, M. L. Tang, J. R. Long and C. J. Chang, J. Am. Chem. Soc., 2011, 133, 9212-9215.

21 D. J. Wasylenko, C. Ganesamoorthy, J. Borau-Garcia and C. P. Berlinguette, ChemComm, 2011, 47, 4249-4251.

22 D. J. Wasylenko, R. D. Palmer, E. Schott and C. P. Berlinguette, ChemComm, 2012, 48, 2107-2109.

23 L. Wang, L. Duan, R. B. Ambre, Q. Daniel, H. Chen, J. Sun, B. Das, A. Thapper, J. Uhlig, P. Dinér and L. Sun, J. Catal., 2016, 335, 72-78.

24 S. Ohzu, T. Ishizuka, H. Kotani and T. Kojima, ChemComm, 2014, 50, 15018-15021.

25 B. Das, A. Orthaber, S. Ott and A. Thapper, ChemComm, 2015, 51, 13074-13077.

26 B. Das, A. Orthaber, S. Ott and A. Thapper, ChemSusChem, 2016, 9, 1178-1186.

27 J. N. Harvey, in Principles and Applications of Density Functional Theory in Inorganic Chemistry I, ed. N. Kaltsoyannis and J. E. McGrady, Springer Berlin Heidelberg, Berlin, Heidelberg, 2004, pp. 151-184.

28 M. Swart, A. R. Groenhof, A. W. Ehlers and K. Lammertsma, J. Phys. Chem. A, 2004, 108, 5479-5483.

29 M. Radoń, Phys. Chem. Chem. Phys., 2014, 16, 14479-14488. 30 B. Pinter, A. Chankisjijev, P. Geerlings, J. N. Harvey and F. De Proft, Chem. - Eur. J., 2018, 24, 5281-5292. 
31 W. Klaeui, W. Eberspach and P. Guetlich, Inorg. Chem., 1987, 26, 3977-3982.

32 J. Li, C. L. Fisher, J. L. Chen, D. Bashford and L. Noodleman, Inorg. Chem., 1996, 35, 4694-4702.

33 R. Gilson and M. C. Durrant, Dalton Trans., 2009, 1022310230.

34 S. V. Jerome, T. F. Hughes and R. A. Friesner, J. Phys. Chem. $B, 2014,118,8008-8016$.

35 M.-H. Baik and R. A. Friesner, J. Phys. Chem. A, 2002, 106, 7407-7412.

36 L. E. Roy, E. R. Batista and P. J. Hay, Inorg. Chem., 2008, 47, 9228-9237.

37 A. V. Marenich, J. Ho, M. L. Coote, C. J. Cramer and D. G. Truhlar, Phys. Chem. Chem. Phys., 2014, 16, 1506815106.

38 L. E. Roy, E. Jakubikova, M. G. Guthrie and E. R. Batista, J. Phys. Chem. A, 2009, 113, 6745-6750.

39 J. Cheng, X. Liu, J. VandeVondele, M. Sulpizi and M. Sprik, Acc. Chem. Res., 2014, 47, 3522-3529.

40 D. Bím, L. Rulíšek and M. Srnec, J. Phys. Chem. Lett., 2016, 7, 7-13.

41 P. Guionneau, M. Marchivie, G. Bravic, J.-F. Létard and D. Chasseau, in Spin Crossover in Transition Metal Compounds II, ed. P. Gütlich and H. A. Goodwin, Springer Berlin Heidelberg, Berlin, Heidelberg, 2004, pp. 97-128.

42 M. Lundberg and P. E. M. Siegbahn, Phys. Chem. Chem. Phys., 2004, 6, 4772-4780.

43 K. Nakamoto, Infrared and Raman Spectra of Inorganic and Coordination Compounds, 4th edn, 1986.

44 B. A. I. Bruker, APEX2 and SAINT., Bruker AXS Inc., Madison, Wisconsin, USA, 2007.

45 G. Sheldrick, Acta Crystallogr., Sect. C: Struct. Chem., 2015, 71, 3-8.

46 G. Sheldrick, Acta Crystallogr., Sect. A: Found. Crystallogr., 2008, 64, 112-122.

47 O. V. Dolomanov, L. J. Bourhis, R. J. Gildea, J. A. K. Howard and H. Puschmann, J. Appl. Crystallogr., 2009, 42, 339-341.
48 A. L. Ankudinov, B. Ravel, J. J. Rehr and S. D. Conradson, Phys. Rev. B: Condens. Matter Mater. Phys., 1998, 58, 75657576.

49 M. Risch, K. Klingan, J. Heidkamp, D. Ehrenberg, P. Chernev, I. Zaharieva and H. Dau, ChemComm, 2011, 47, 11912-11914.

50 J. Yeo, M. H. Cheah, M. I. Bondin and S. P. Best, Aust. J. Chem., 2012, 65, 241-253.

51 M. J. Frisch, G. W. Trucks, H. B. Schlegel, G. E. Scuseria, M. A. Robb, J. R. Cheeseman, G. Scalmani, V. Barone, G. A. Petersson, H. Nakatsuji, X. Li, M. Caricato, A. Marenich, J. B. Bloino, G. R. Janesko, B. Gomperts, H. Mennucci, P. Hratchian, J. V. Ortiz, A. F. Izmaylov, J. L. Sonnenberg, D. Williams-Young, F. Ding, F. Lipparini, F. Egidi, J. Goings, B. Peng, A. Petrone, T. Henderson, D. Ranasinghe, V. G. Zakrzewski, J. Gao, N. Rega, G. Zheng, W. Liang, M. Hada, M. Ehara, K. Toyota, R. Fukuda, J. Hasegawa, M. Ishida, T. Nakajima, Y. Honda, O. Kitao, H. Nakai, T. Vreven, K. Throssell, J. A. Montgomery, J. E. Peralta Jr., F. Ogliaro, M. Bearpark, J. J. Heyd, E. Brothers, K. N. Kudin, V. N. Staroverov, T. Keith, R. Kobayashi, J. Normand, K. Raghavachari, A. Rendell, J. C. Burant, S. S. Iyengar, J. Tomasi, M. Cossi, J. M. Millam, M. Klene, C. Adamo, R. Cammi, J. W. Ochterski, R. L. Martin, K. Morokuma, O. Farkas, J. B. Foresman and D. J. Fox, Gaussian, Inc., Wallingford CT, 2009.

52 M. Reiher, O. Salomon and B. A. Hess, Theor. Chem. Acc., 2001, 107, 48-55.

53 S. Grimme, J. Antony, S. Ehrlich and H. Krieg, J. Chem. Phys., 2010, 132, 154104.

54 A. V. Marenich, C. J. Cramer and D. G. Truhlar, J. Phys. Chem. B, 2009, 113, 6378-6396.

55 R. S. Greeley, W. T. Smith Jr., R. W. Stoughton and M. H. Lietzke, J. Phys. Chem., 1960, 64, 652-657.

56 A. A. Isse and A. Gennaro, J. Phys. Chem. B, 2010, 114, 7894-7899. 